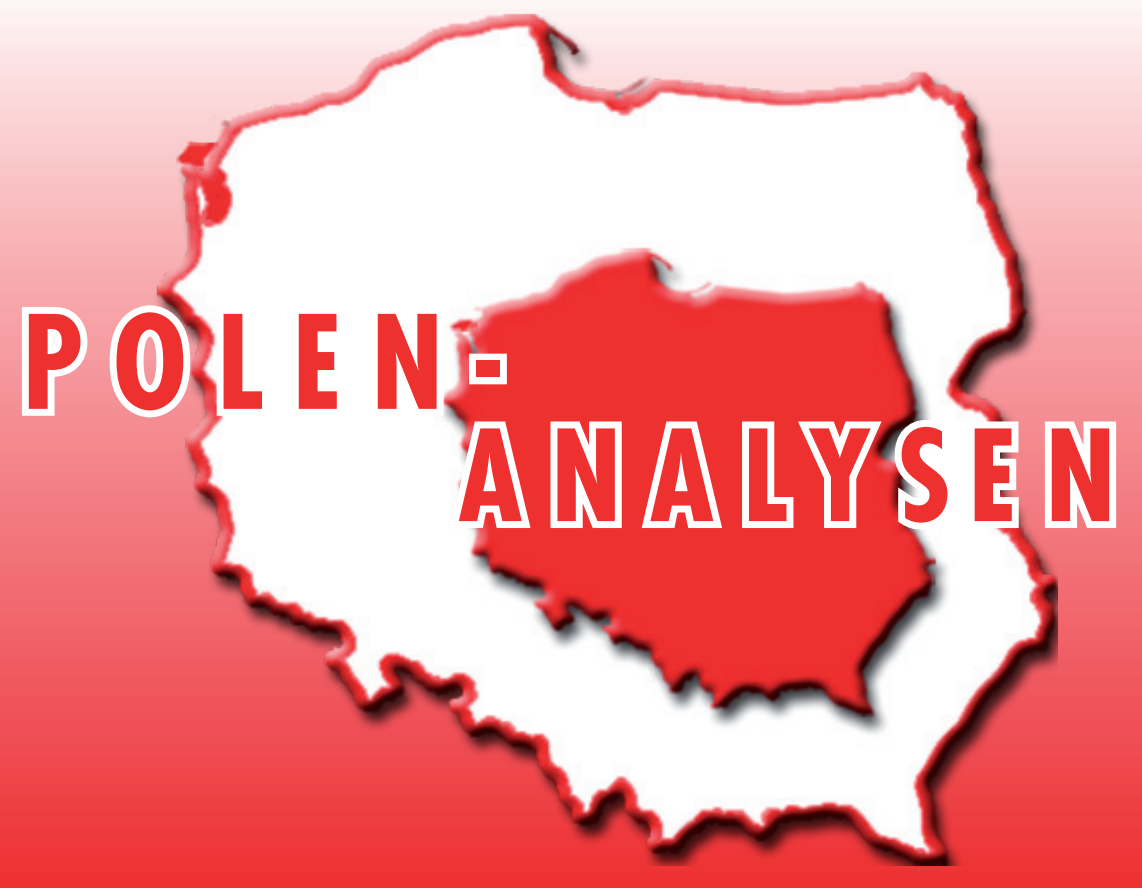

www.laender-analysen.de/polen

\title{
DAS JAHR 1989 IN DER POLNISCHEN ERINNERUNG
}

\section{ANALYSE}

Das Schlüsseljahr 1989 in der polnischen Erinnerung

Reinhold Vetter, Warschau/Berlin

\section{口 DOKUMENTATION}

Warschauer Freiheitserklärung

- UMFRAGE

Meinungen zu 1989

\section{CHRONIK}

1. Juli - 1. September 2014 


\section{Das Schlüsseljahr 1989 in der polnischen Erinnerung}

Reinhold Vetter, Warschau/Berlin

\section{Zusammenfassung}

Die bahnbrechenden Ereignisse vor 25 Jahren dominieren seit dem Frühjahr 2014 die offizielle Geschichtspolitik und das historische Gedenken in Polen. Dabei überwiegt zwar die positive Bewertung der damals begonnenen Transformation, doch einzelne Aspekte wie die harten marktwirtschaftlichen Reformen sind bis heute umstritten. Geht es um eine Bilanz, was Polen in den letzten 25 Jahren erreicht hat, dann dominieren auch hier die positiven Meinungen in der Gesellschaft, wenngleich auch viele kritische Stimmen laut wurden. Traditionell zeigt sich, dass die Erinnerung sehr stark vom heutigen politischen Standpunkt der Betrachter abhängig ist. Bemerkenswert ist außerdem, dass neben den Ereignissen des Jahres 1989 auch und gerade das Geschehen des Ersten Weltkrieges stärker in den historischen Fokus der Gesellschaft rückte.

1 989 zählt zu den Schlüsseldaten des 20. Jahrhunderts - auch und gerade in Polen. In jenem Jahr wurden die Weichen für den Systemwechsel gestellt. Ziel der Transformation war es, den Einparteienstaat durch eine demokratische Republik mit einem frei gewählten Parlament und einem pluralistischen Parteiensystem zu ersetzen. Bis dato war der absolute Führungsanspruch der Polnischen Vereinigten Arbeiterpartei (PZPR) verfassungsrechtlich legitimiert und wurde in Politik, Wirtschaft und Gesellschaft durchgesetzt. Die ebenfalls existierenden sogenannten Blockparteien Demokratische Partei (SD) und Vereinigte Volkspartei (ZSL) spielten keine eigenständige Rolle. Allerdings hatte die PZPR schon in den 1980er Jahren ideologisch und politisch abgewirtschaftet. Nach Verhängung des Kriegsrechts im Dezember 1981 gewährleistete das Militär zunehmend die Aufrechterhaltung der Strukturen des sozialistischen Staates.

Die Volksrepublik Polen war darüber hinaus auch kein Rechtsstaat, in dem Gleichheit vor dem Gesetz herrschte und die Menschen- und Bürgerrechte für alle Mitglieder der Gesellschaft verbindlich galten. Vielmehr bestimmten ideologische Grundsätze das sozialistische Rechtssystem, die dazu führten, dass wichtige Grundrechte wie das der Meinungs-, Versammlungs- und Vereinigungsfreiheit nicht gegeben waren. Im Jahr 1989 stand also auch der Aufbau eines wirklichen Rechtsstaats auf der Tagesordnung.

Außerdem ging es darum, das sozialistische System der Staatswirtschaft, in dem die PZPR und die von ihr gestellte Regierung die wichtigsten wirtschaftlichen Entscheidungen trafen, durch eine moderne Marktwirtschaft zu ersetzen, in der privates Unternehmertum die wichtigste Form wirtschaftlicher Tätigkeit ist und der Markt bzw. die Konkurrenz die ökonomische Entwicklung bestimmen. Das freie Wirken des Marktes sollte auf der anderen Seite durch ein modernes Sozialsystem ausgeglichen werden.

\section{Ein Jahr großer politischer Dynamik}

Zunächst stand im Frühjahr 2014 der "Runde Tisch» im Zentrum der kollektiven Erinnerung in Polen. Mit einer Vielzahl von Analysen, Erinnerungen und Berichten in den Medien, mit öffentlichen Ansprachen, Konferenzen, Gedenkveranstaltungen und Ausstellungen bemühten sich Politiker, Wissenschaftler und Publizisten, das historische Geschehen erneut ins Bewusstsein der Gesellschaft und besonders der jungen Generation zu holen.

Im Februar, März und April 1989 waren am Runden Tisch die ersten Schritte der Transformation in Polen ausgehandelt worden. Politisch bedeutete »rund" nichts anderes, als dass sich Vertreter der Gewerkschaft Solidarität (Solidarność) und anderer wichtiger Strömungen der politischen Opposition gemeinsam mit Repräsentanten der kommunistischen Staats- und Parteiführung unter der Moderation der katholischen Kirche an einen Tisch setzten, um auf friedlichem Weg den Übergang vom Sozialismus zu einer parlamentarischen Demokratie auszuhandeln. Nach zweimonatigen Verhandlungen hatte man sich darauf verständigt,

- die Solidarność wieder legal arbeiten zu lassen,

- schrittweise zu freien Parlamentswahlen zu kommen,

- einen Senat zu bilden, der den Sejm als erste Parlamentskammer kontrollieren sollte, und

- einen Staatspräsidenten zu wählen.

Adam Michnik, einer der Protagonisten der Opposition am Runden Tisch und seit 1989 Chefredakteur der Tageszeitung Gazeta Wyborcza, bezeichnete zum diesjährigen Jahrestag die damaligen erfolgreichen Verhandlungen als eine der größten Errungenschaften des modernen Polen. In einem vom Aufständen, Kriegen und blutigen Niederlagen geprägten Land, so Michnik, hätten beide Seiten den friedlichen Dialog gewählt. Die führende Wochenzeitung Polityka erinnerte daran, dass der britische Historiker Timothy Garton Ash den Runden Tisch als "refolucja» (eine Mischung aus Revolution und Reform - R.V.) bezeichnet hatte. Und der polnische 
Staatspräsident Bronisław Komorowski, der in einem Interview mit Polityka freimütig eingeräumt hatte, dass er damals den Gesprächen am Runden Tisch misstraut und diese nur als taktische Variante der Kommunisten zum Erhalt ihrer Macht betrachtet habe, sagte während einer Konferenz in seinem Amtssitz, eben dieser Runde Tisch sei eine außerordentlich wichtige Etappe auf dem Weg Polens zu Freiheit und Souveränität gewesen.

Es war der ehemalige polnische Staatspräsident Aleksander Kwaśniewski, der schon im sozialistischen Polen Karriere gemacht und sich später zum Sozialdemokraten gemausert hatte, der bei eben dieser Konferenz im Warschauer Präsidentenpalais daran erinnerte, dass der Runde Tisch ein originär polnisches Konzept gewesen war, das später aber auch in Ungarn, der DDR und der Tschechoslowakei Nachahmung gefunden hatte.

Repräsentanten der damaligen Opposition wie Henryk Wujec gaben offen zu, dass in jener Zeit in ihren Reihen große Unsicherheit geherrscht habe, ob "die Kommunisten« den Runden Tisch wirklich ernst nähmen oder ob sie vielleicht planten, die Opposition zu überrumpeln. Sein Kollege Władysław Frasyniuk, ebenfalls Teilnehmer am Runden Tisch, berichtete, wie schwer es ihm damals gefallen sei, Vertretern der kommunistischen Macht wie dem damaligen Innenminister Czesław Kiszczak vor Beginn der Verhandlungen die Hand zu geben.

Auf jeden Fall, so der polnische Soziologe Edmund Wnuk-Lipiński in dem polnisch-deutschen Magazin Dialog, sei sich wohl keiner der Teilnehmer des Runden Tisches, weder aus den Reihen der Machthaber noch der Opposition, vollkommen dessen bewusst gewesen, welche radikalen Folgen dieser für das System in Polen noch im selben Jahr haben würde.

\section{"Herz der polnischen Demokratie"}

Im Frühsommer 2014 rückte die Parlamentswahl vom Juni 1989 ins Zentrum des Gedenkens, was vor allem auf die Einflussnahme von Staatspräsident Bronisław Komorowski zurückging. In einem Interview mit Polityka begründete er dies mit dem Hinweis, dass der plebiszitäre Charakter dieser Wahl ganz entscheidend für die weitere politische Entwicklung gewesen sei. Polens Volksheld Lech Wałęsa kommentierte diese Schwerpunktsetzung des Staatsoberhaupts mit dem süffisanten Hinweis auf die Tatsache, dass Komorowski damals nicht zur Wahl gegangen war, weil er sie als mögliches kommunistisches Betrugsmanöver eingeschätzt hatte.

In der ersten Runde der »halbfreien« Wahl am 4. Juni 1989 errangen die Solidarność und die ganze Opposition einen grandiosen Sieg. Auf Anhieb erzielten ihre Kandidaten 160 von 161 möglichen Mandaten im Sejm und 92 von 100 Mandaten im Senat. Demgegenüber schei- terten fast alle Kandidaten der $P Z P R$ und der Regierung wegen ihres niedrigen Wahlergebnisses. »Halbfrei« bedeutete, dass aufgrund der Absprachen am Runden Tisch 65 Prozent der Sitze im Sejm (299 von insgesamt 460) der PZPR und ihren Blockparteien vorbehalten blieben - unabhängig vom Wahlergebnis. Diese Regelung sollte den bisherigen Machthabern den Übergang in die neue Demokratie erleichtern. Erst nach einer Wahlrechtsänderung, die für erhebliche Kontroversen innerhalb der Opposition sorgte, erzielten diese Parteien in einer zweiten Wahlrunde am 18. Juni die für sie reservierten Mandate.

Zum 25. Jahrestag räumten führende Köpfe beider Seiten von damals ein, dass man von diesem Wahlergebnis völlig überrascht gewesen sei. Die bald nach der Wahl einsetzende Diskussion, ob die Solidarność nun Regierungsverantwortung übernehmen solle, habe, so Lech Wałęsa, ihn und seine Mitstreiter völlig unvorbereitet getroffen. Wałęsa wies andererseits aber auch darauf hin, dass der damalige Wahlerfolg weltweit Aufsehen erregt habe. Adam Michnik zog sogar einen Vergleich zur Niederschlagung des Bürgerprotestes auf dem Tiananmen-Platz in Peking im Juni 1989, um die internationale Bedeutung des friedlichen Wandels im damaligen Polen hervorzuheben.

In einer Rede vor der Nationalversammlung (Sejm und Senat) am 4. Juni dieses Jahres betonte Staatspräsident Bronisław Komorowski, dass das Parlament mit der Wahl vor 25 Jahren seine Rolle als »Herz der polnischen Demokratie« wiedererlangt habe. Aber er nutzte seinen Auftritt auch, um künftige Aufgaben seines Landes zu benennen, insbesondere eine sozialpolitische Reform zur Vermeidung von Massenarmut und eine baldige öffentliche Debatte über den Beitritt Polens zur Eurozone. Die Abgeordneten beider Kammern verabschiedeten außerdem die "Warschauer Freiheitserklärung" (Warszawska Deklaracja Wolności), in der es unter anderem hieß, dass der damalige Sieg der Solidarność am Anfang der großen Systemveränderungen in allen Staaten Ostmitteleuropas gestanden habe.

Glaubt man den Reden vieler Politiker und dem dominierenden Tenor in den großen Medien des Landes, dann wertete die Mehrheit der polnischen Gesellschaft den Auftritt des amerikanischen Präsidenten Barack Obama am 4. Juni dieses Jahres in Warschau als große Anerkennung für den Weg, den Polen in den letzten 25 Jahren gegangen ist.

Der dritte Schwerpunkt des Gedenkens in diesem Jahr war die Erinnerung an die Bildung der ersten nicht kommunistisch geführten Regierung im August/September 1989. Das dreimonatige Tauziehen nach der Wahl im Juni hatte schließlich zur Bestätigung des neuen Kabinetts von Ministerpräsident Tadeusz Mazowiecki 
durch den Sejm am 12. September geführt. Einen wichtigen Anstoß zu diesem Erfolg hatte Adam Michnik am 3. Juli mit seinem Text »Euer Präsident, unser Ministerpräsident" (Wasz Prezydent, nasz premier) in der Gazeta Wyborcza gegeben.

Das von Michnik bis heute geführte Blatt war am 8. Mai 1989 zum ersten Mal erschienen und hatte eine enorm wichtige Rolle im Wahlkampf der Solidarność bzw. der ganzen Opposition gespielt.

Seither hat die Bedeutung der sozialliberal ausgerichteten Gazeta Wyborcza (übersetzt: Wahlzeitung) etwas abgenommen, auch wenn sie immer noch zu den drei größten polnischen Tageszeitungen zählt. Zu ihrem 25jährigen Bestehen schrieb Adam Michnik mit einem Schuss Selbstironie: "Nie haben wir uns gleichgültig verhalten; wenn die Wahrheit und die Freiheit bedroht waren, haben wir - mitunter auch überzogen - reagiert."

Aus zeithistorischer Sicht ist es wohl nicht übertrieben, wenn man zu dem Schluss kommt, dass das Kabinett von Mazowiecki den schwierigsten "Job«aller polnischen Regierungen der letzten 25 Jahre hatte. Bahnbrechend waren vor allem die wirtschafts- und finanzpolitischen Beschlüsse dieses Kabinetts. Auf der Grundlage eines Konzepts des damaligen Finanzministers Leszek Balcerowicz, "Schocktherapie« genannt, gelang es, die horrende Inflation und Staatsverschuldung zu bremsen sowie Grundlagen für eine liberale und soziale Marktwirtschaft zu legen. Die neue Regierung konzentrierte sich aber auch auf verfassungsrechtliche und institutionelle Veränderungen. Außerdem definierte sie die polnische Außenpolitik völlig neu.

In seiner Rede vor der Nationalversammlung am 4. Juni dieses Jahres sagte Staatspräsident Bronisław Komorowski: „Die Regierung von Tadeusz Mazowiecki genoss die absolute Unterstützung (der Bevölkerung R.V.) und verfügte über eine gigantische Mehrheit im Sejm, sie leistete eine Pionierarbeit, wie sie vordem niemand vollbracht hatte."

Schon der Tod von Tadeusz Mazowiecki am 28. Oktober 2013 war ein entscheidender Anlass für die polnische Öffentlichkeit gewesen, die Verdienste dieses Mannes zu würdigen, der zu den wichtigsten Akteuren des antikommunistischen Widerstandes, des Übergangs zur Demokratie und des Aufbaus eines neuen Staatswesens zählte. Charakteristisch für Mazowieckis Wirken in der Politik, so hieß es mehrfach, sei sein kategorischer moralischer Imperativ gewesen, den er aber klar abzugrenzen wusste von einem Habitus des billigen Moralisierens.

Spätestens seit 1989 genoss der Katholik Mazowiecki bei vielen Polen hohes Ansehen, auch wenn er bei der Präsidentenwahl 1990 eine schmerzliche Niederlage erlitt und später parteipolitisch nicht immer besonders glücklich agierte.
Am 30. August dieses Jahres eröffnete das Europäische Zentrum der Solidarität (Europejskie Centrum Solidarności - ECS) an seinem neuen Sitz in Danzig (Gdańsk) eine Dauerausstellung zur Geschichte der Solidarność und der Systemtransformation in Polen. Einen Tag später, 34 Jahre nach Unterzeichnung des historischen "Danziger Abkommens" zwischen den streikenden Arbeitern und der Regierung, wurde das neue ECS-Gebäude in Anwesenheit von Staatspräsident Bronisław Komorowski offiziell eröffnet. Die Ausstellung ist nun das Herzstück des im November 2007 gegründeten und von Basil Kerski geleiteten ECS, das sich als kulturelles und pädagogisches Zentrum versteht. In seinen neuen Räumen unweit der Danziger Werft befinden sich auch eine Bibliothek und ein Archiv.

\section{Bis heute umstritten: die »Schocktherapie» und der "dicke Strich"}

Die öffentliche Debatte über die Ereignisse des Jahres 1989 zeigt, dass innerhalb der politischen Klasse Polens bis heute vor allem zwei Phänomene umstritten sind: die vom damaligen Finanzminister Leszek Balcerowicz initiierten marktwirtschaftlichen Reformen sowie die Art und Weise, wie die Regierung von Tadeusz Mazowiecki mit den politischen und juristischen Hinterlassenschaften des vormaligen kommunistischen Regimes umging.

In Sachen Balcerowicz sagte Staatspräsident Komorowski in der Polityka, es sei notwendig gewesen, den Kapitalismus aufzubauen, wie man ihn damals verstanden habe. Und wörtlich: „Ohne den BalcerowiczPlan [...] hätten wir uns in eine Position gebracht, aus der heraus wir uns nur langsam vom ökonomischen Kollaps geheilt hätten. «Die Gegenposition formulierten vor allem Vertreter der politischen Rechten, etwa der Gruppierung Solidarna Polska. Sie sprachen davon, dass die Anliegen der Gesellschaft im Denken von Balcerowicz keine Rolle gespielt hätten. Aber auch die Sozialdemokraten der Demokratischen Linksallianz (Sojusz Lewicy Demokratycznej-SLD) sahen Balcerowicz eher kritisch und forderten die Bildung eines Fonds für Ausgleichszahlungen (Fundusz Rekompensat Transformacji Ustrojowej) an diejenigen, die damals ihre Arbeit verloren hatten.

Wirtschaftswissenschaftler aus Ost und West sind sich heute darin einig, dass die von Balcerowicz im Dezember 1989 durch den Sejm gebrachten Gesetze sinnvoll waren. Andererseits waren bestimmte Folgen dramatisch. Schon bald fielen die Reallöhne, die Produktion ging zurück, die Arbeitslosigkeit stieg an, Polen geriet in eine sogenannte Transformationsrezession.

Auch die Politik des »dicken Strichs", wie der damalige Ministerpräsident Tadeusz Mazowiecki seinen Umgang mit den kommunistischen Hinterlassen- 
schaften umschrieb, sorgt bis heute für Widerspruch. Mazowiecki meinte damit den Vorrang der politischen und ökonomischen Erneuerung Polens vor der ideologisch-politischen und juristischen Abrechnung mit dem früheren System und dessen Repräsentanten. Vertreter der politischen Rechten betonten jetzt, »viele Verbrecher aus kommunistischen Zeiten« seien straffrei ausgegangen, der Staatsapparat sei zu wenig von Kadern aus alten Zeiten gesäubert werden. Bei politischen Demonstrationen der Partei Recht und Gerechtigkeit (Prawo i Sprawiedliwość-PiS) von Jarosław Kaczyński wurden gerade in diesem Zusammenhang auch Parolen laut, das Jahr 1989 sei letztendlich "nationaler Verrat" gewesen.

Tatsache ist, dass die polnische Gesellschaft überfordert gewesen wäre, wenn sie neben den harschen politisch-ökonomischen Reformen der Jahre 1989/90 auch noch eine radikale "Dekommunisierung " samt all der damit verbundenen Konflikte hätte aushalten müssen. Andererseits haben es die auf Mazowiecki folgenden Regierungen versäumt bzw. waren nicht daran interessiert, das Problem anzugehen und die einschlägigen Akten aus kommunistischen Zeiten, wie in Deutschland die sogenannte Gauck-Behörde, der polnischen Öffentlichkeit zugänglich zu machen.

Eine Reihe von Umfragen und Analysen verschiedener Meinungsforschungsinstitute gibt wieder, was die polnischen Bürger heute über die Transformation des Jahres 1989 denken. So bewerten laut dem Zentrum zur Erforschung der öffentlichen Meinung (Centrum Badania Opinii Spotecznej-CBOS) 42 Prozent der Gesellschaft die Beschlüsse des Runden Tisches mehr oder weniger positiv. 10 Prozent lehnen sie ab und 48 Prozent interessieren sich nicht dafür oder sehen sich zu keinem Urteil in der Lage. Dabei fällt auf, dass die Bewertung stark von den jeweiligen Parteipräferenzen der Befragten abhängt. So haben 69 Prozent der Anhänger der Bürgerplattform (Platforma Obywatelska-PO) und 56 Prozent der SLD eine positive Meinung über den Runden Tisch, während nur 37 Prozent der Wähler von PiS diese Ansicht vertreten. Bemerkenswert ist außerdem, dass 52 Prozent meinen, der Runde Tisch sei hauptsächlich ein Kompromiss zwischen den damaligen Eliten der Solidarność und den kommunistischen Machthabern gewesen, während nur 17 Prozent das damalige Geschehen für eine demokratische Revolution halten, bei der gesellschaftlicher Druck das totalitäre System zum Einsturz gebracht habe.

Vermutlich stimmt die Einschätzung, die der verstorbene Mittelalterhistoriker, Bürgerrechtler und Außenminister Bronisław Geremek bereits 2009 vortrug. Geremek meinte, die Transformation habe drei Schwächen gehabt:

- Man habe damals die Bürger zu wenig in die Debatte über die Konzepte des Systemwechsels miteinbezogen,
- die Menschen seien nicht ausreichend von der absoluten Notwendigkeit der »Schocktherapie« überzeugt worden und

- die Mehrheit der Elite der Solidarność habe die Langlebigkeit kommunistischer und postkommunistischer Denk- und Verhaltensweisen auch nach der Transformation unterschätzt.

Interessant ist in diesem Zusammenhang eine 2014 publizierte Liste "wichtiger Persönlichkeiten«, die auf Grundlage einer Befragung zusammengestellt wurde. Auf die Frage, wer den größten Einfluss auf die Entwicklung der Dritten Polnischen Republik, also der Zeit seit 1989, ausgeübt habe, nannten 55 Prozent der Befragten Lech Wałęsa. Auf Platz 2 und 3 folgten Aleksander Kwaśniewski mit 24 Prozent und Tadeusz Mazowiecki mit 23 Prozent. Leszek Balcerowicz (Platz 7) und Wojciech Jaruzelski (Platz 8) kamen auf 16 bzw. 15 Prozent, während Jarosław Kaczyński (Platz 12) bei 8 Prozent sowie Bronisław Geremek (Platz 13) und der SLD-Politiker Leszek Miller (Platz 14) bei jeweils 7 Prozent landeten.

Sieht man einmal davon ab, ob dieses Umfrageergebnis dem realen Einfluss der Genannten tatsächlich entspricht, zeigt sich doch ein buntes Bild von antikommunistischen und postkommunistischen Politikern sowie führenden Akteuren rechter und linker Parteien. Nur recht und billig war es dann, dass Adam Michniks Gazeta Wyborcza Anfang Juni 2014 den Spitzenreiter, eben Lech Wałęsa, zum »Mann des Vierteljahrhunderts" kürte.

Kurz zuvor, am 25. Mai, war Wojciech Jaruzelski verstorben. Der Tod des Generals war zum wiederholten Mal Anlass einer scharfen öffentlichen Auseinandersetzung über diesen Mann, dessen Name sich für die meisten Polen vor allem mit der Verhängung des Kriegsrechts am 13. Dezember 1981 verbindet. Und wie so oft folgte das Gros der Stellungnahmen dem bekannten ideologischen Strickmuster. Entweder wurde der General nur als kommunistischer Diktator, Verräter an der Nation oder gar als Mörder tituliert, so vor allem von Seiten konservativer und nationalistischer Politiker, Historiker und Publizisten, oder man stilisierte ihn ausschließlich als verantwortungsvollen Patrioten, der Polen vor einer sowjetischen Invasion bewahrt habe, so insbesondere in Kreisen der sozialdemokratischen SLD, deren Wurzeln bis zur alten kommunistischen Staatspartei PZPR reichen.

Eine der wenigen differenzierten Stellungnahmen veröffentlichte Polityka, in der einerseits die Rede von den schwarzen Flecken in der Biographie Jaruzelskis war, also seine Beteiligung am militärischen Kampf gegen den antikommunistischen Widerstand 1944-45, seine militärische Karriere im Stalinismus, seine Ver- 
antwortung für die antijüdischen Säuberungen in der Armee 1967 und die gewaltsame Niederschlagung der Arbeiterproteste im Dezember 1970, andererseits seine Verdienste auf Seiten der machthabenden Kommunisten für die friedliche Transformation 1989 hervorgehoben wurden.

\section{Was wurde seit 1989 erreicht?}

Erinnern bedeutet immer auch Bilanz ziehen. In den vergangenen 25 Jahren hat sich Polen zu einer respektablen demokratischen Republik entwickelt, das Parteiensystem und der Parlamentarismus funktionieren, Machtwechsel durch demokratische Wahlen sind gewährleistet. Der Rechtsstaat existiert, bedarf aber weiterer Entwicklung. Es bleibt abzuwarten, welche Gefahren für die Dreiteilung der Staatsgewalt, die Minderheitenrechte und den Pluralismus in Kultur, Wissenschaft, Erziehung und Medien drohen, sollten der nationalistisch denkende Jarosław Kaczyński und seine Partei PiS im Jahr 2015 die Regierungsverantwortung übernehmen.

Seit einigen Jahren wird die polnische Volkswirtschaft sogar im Westen gelobt. Sie hat eine beachtliche Leistungsfähigkeit entwickelt, operiert aber noch nicht auf dem Niveau westeuropäischer Volkswirtschaften. Der Ökonom Dariusz Filar vertritt zu Recht die Auffassung, dass Polen inzwischen nicht mehr nur auf den Zufluss ausländischer Technologien angewiesen sei, sondern über eine wachsende Zahl eigener Unternehmen verfüge, die, global gesehen, auf den modernsten Standards produzierten und auf dem Weltmarkt konkurrenzfähig seien.

Zur Bilanz der vergangen 25 Jahre gehört auch, dass Polen aufgrund der 1999 und 2004 vollzogenen Mitgliedschaft in die NATO bzw. die Europäische Union international gesehen in einem vergleichsweise sicheren Umfeld agiert. Die Mehrheit der Polen spürt, dass ihr Land an Ansehen auf der internationalen Bühne gewonnen hat. Allerdings hat die Krise zwischen Russland und der Ukraine dieses Sicherheitsgefühl etwas ins Wanken gebracht.

Es bleibt allerdings die Frage, wie sich diese Errungenschaften in der gesellschaftlichen Realität widerspiegeln und das Denken und Handeln der Menschen in Polen beeinflussen. Antworten lassen sich in den Analysen renommierter Soziologen wie Edmund Wnuk-Lipiński und Janusz Czapiński, in der alle zwei Jahre erarbeiteten »Gesellschaftsdiagnose« (Diagnoza spoteczna) sowie in den Umfragen von Instituten wie CBOS und TNS Polska finden.

Noch immer herrscht bei vielen Menschen in Polen die tief in der Tradition verankerte Haltung vor, die genannten Errungenschaften entweder zu ignorieren oder sie als Ausdruck einer Erfolgspropaganda bzw. gar als Verfälschung der Wirklichkeit zu betrachten - ganz im Gegensatz zu Beobachtern Polens im Ausland. So ist es nicht weiter verwunderlich, wenn in einer Umfrage von $C B O S$ nur 45 Prozent der Befragten meinten, die letzten 25 Jahre hätten mehr Vorteile als Nachteile gebracht, während 27 Prozent eine gemischte Bilanz zogen und 28 Prozent von überwiegenden Verlusten sprachen oder überhaupt keine Meinung dazu hatten.

Auffallend ist weiterhin das tiefe Misstrauen, das die polnische Gesellschaft prägt. Umfragen und Studien haben ergeben, dass nur 10 bis 20 Prozent der Polen Vertrauen zu ihren sie umgebenden Mitmenschen haben. Wnuk-Lipiński in Dialog (01/2014): „Das niedrige Niveau des sozialen Vertrauens (eines der niedrigsten in Europa) erhöht die Kosten aller Transaktionen, stört die täglichen zwischenmenschlichen Beziehungen und ist ein guter Nährboden für die Entwicklung von extrem partikularistischen Haltungen.»

Des Weiteren zeigen sich tiefe Risse in der Gesellschaft, die nicht selten entlang den Spaltungen zwischen parteipolitischen Sympathien und politischen Strömungen verlaufen. Die Polarisierung ist oft so stark, dass die Protagonisten und Anhänger bestimmter Gruppen die ökonomische und soziale Realität oft völlig unterschiedlich beschreiben und bewerten. Gegenseitige Abneigung bis hin zum Hass sowie lautstark zum Ausdruck gebrachte Emotionen lassen oft wenig Raum für Kompromisse und blockieren so die zukunftsträchtige Entwicklung des Gemeinwesens.

Janusz Czapiński, Professor für Psychologie an der Universität Warschau, spricht davon, dass es in der polnischen Gesellschaft viel individuelles Kapital, also Bildung, Engagement und Leistungswillen, aber wenig kollektive Ressourcen gebe, also wenig Bereitschaft, gemeinsame Interessen zu vertreten. Zwar geben die von $C B O S$ Befragten an, die erlangte Freiheit sei die wichtigste Errungenschaft der letzten 25 Jahre, sie verstehen diese aber ausschließlich als individuelles Privileg, nicht als Raum für kollektive Anstrengungen. Gerade die vielen jungen Anhänger von Janusz Korwin-Mikke und seiner Partei Neue Rechte (Nowa Prawica) denken auf diese Weise.

Damit hängt auch zusammen, dass die meisten Polen vor allem stolz auf die eigenen Leistungen und auf ihre Familie sind, aber dem Gemeinwesen und seinen Institutionen nur sehr bedingt Anerkennung zollen. Aus einer Umfrage von $C B O S$ geht hervor, dass die Menschen insbesondere dem Militär (74 Prozent der Befragten), der Polizei (71 Prozent) und der katholischen Kirche (64 Prozent) vertrauen, aber dem Parlament (nur 34 Prozent der Befragten), der Regierung (33 Prozent) und den politischen Parteien (17 Prozent) eher misstrauen. Die jüngste "Abhöraffäre«, von der führende $P O$-Politi- 
ker und Wirtschaftsvertreter betroffen sind, dürfte den politischen Institutionen noch weiter geschadet haben.

Die Mehrheit der Polen vertritt die Auffassung, dass der Lebensstandard der Gesellschaft in den letzten 25 Jahren generell erheblich angestiegen ist. Registriert wird aber auch, dass sich der Graben zwischen den Beziehern hoher und niedriger Einkommen, generell zwischen arm und reich, stetig vertieft hat. "Ich halte die offene und verdeckte Arbeitslosigkeit, die Emigration und die Ungleichheit in der Gesellschaft für unsere größte Niederlage «, betont der Historiker, Bürgerrechtler und ehemalige Politiker der Arbeitsunion (Unia Pracy), Karol Modzelewski.

\section{Fazit}

Ohne Zweifel haben die Ereignisse von 1989 die polnische Öffentlichkeit in diesem Jahr intensiv beschäftigt. Vor allem Staatspräsident Bronisław Komorowski, aber auch Ministerpräsident Donald Tusk und andere Politiker sowie Protagonisten des damaligen Geschehens und auch die Mehrheit der Medien des Landes taten alles, um eine »königliche Feiertagsstimmung« zu erzeugen, wie sich der Publizist Krzysztof Gottesman ausdrückte. 1989 ist eben ein Schlüsseljahr der polnischen Zeitgeschichte und damit der kollektiven Erinnerung.

Andererseits herrschte eine Kluft zwischen dem offiziellen »Feiertagsgeschehen « und dem eher mäßigen Interesse breiter Teile der Bevölkerung. Das kann auch gar nicht anders sein, sind doch die aktuellen Probleme des Lebens den Menschen in der Regel näher als historische Reflexionen. Außerdem erinnert man sich hauptsächlich in der eigenen Gruppe, mit der man sich identifiziert, in der Familie, im Freundeskreis, am Arbeitsplatz, mit alten Mitkämpfern aus jenen Zeiten, nicht aber in der öffentlichen bzw. offiziellen Arena.

Hat die Erinnerung zur Versöhnung zwischen den damaligen Kontrahenten beigetragen, die ja zum Teil bis heute im politischen Kampf stehen? Eher weniger. Denn einmal mehr zeigte sich, dass Geschichtsbetrach- tung und Erinnern in Polen bis heute stark politisch instrumentalisiert werden. Eine Annäherung bei der Einschätzung der damaligen Ereignisse fand kaum statt.

Positiv ist sicher, dass die Erinnerung an 1989 das Gedenken an andere historische Ereignisse nicht ganz verdrängt hat. Das gilt besonders für die dramatischen Ereignisse des Ersten Weltkrieges, die zum ersten Mal etwas stärker ins allgemeine Bewusstsein gerückt sind. Bislang war fast ausschließlich das unmittelbare Nachkriegsgeschehen ab 1918 im Denken der interessierten Polen verankert: die staatliche "Wiedergeburt", der Kampf um die Landesgrenzen, der polnisch-sowjetische Krieg von 1920. Das ist verständlich, reicht aber natürlich nicht aus.

Große Beachtung fand in Polen, dass des Warschauer Aufstandes von 1944 in diesem Jahr erstmals auch in Berlin mit einer Ausstellung und dem gemeinsamen Auftritt von Staatspräsident Bronisław Komorowski und Bundespräsident Joachim Gauck gedacht wurde. Die Gazeta Wyborcza nannte dies sogar "ein Wunder in Berlin«. Tatsächlich war in Deutschland bislang fast ausschließlich vom Aufstand im jüdischen Ghetto in Warschau im Jahr 1943 die Rede gewesen.

Schließlich zeigte sich ganz deutlich, wie aktuelle politische Ereignisse Geschichtspolitik und kollektive Erinnerung beeinflussen können. Das galt und gilt besonders für die russisch-ukrainische Krise. In die Genugtuung über die Errungenschaften der 15jährigen Mitgliedschaft in der NATO und der zehnjährigen Zugehörigkeit zur EU mischten sich Bedrohungsängste, die nicht nur aktuelle Ursachen haben, sondern auch an leidvolle historische Erfahrungen Polens mit Russland und der Sowjetunion anknüpfen. Interessant war in diesem Zusammenhang die Diskussion, ob nicht die Ukraine heute einen Runden Tisch brauche, wie er damals als friedliche Methode des Wandels in Polen Geschichte gemacht hat. (Vgl. Polen-Analyse Nr. 147).

\section{Über den Autor}

Reinhold Vetter, Ingenieur und Politikwissenschaftler, lebt als freier Publizist in Warschau und Berlin. 2014 erschien seine Biographie »Bronisław Geremek: der Stratege der polnischen Revolution« im Berliner Wissenschafts-Verlag. 


\section{Warschauer Freiheitserklärung}

Wir, die Bürger des freien und sich vereinigenden Europa, solidarisch in der Liebe zur Freiheit und zu den anderen gemeinsamen Werte, die die Vertreter der Nationen einen, die in Warschau am 4. Juni 2014 versammelt sind, dem 25. Jahrestag des Wahlsieges der polnischen Solidarność, der die großen Systemveränderungen in den Staaten Ostmitteleuropas einleitete,

der historischen Tragweite dieses Umbruchs bewusst, bringen die Überzeugung zum Ausdruck, dass Freiheit und Solidarität fundamentale Werte darstellen, auf die unsere zwischenmenschlichen Beziehungen gründen sollten.

Wir erklären eine tiefe Verbundenheit mit den Werten, die das gemeinsame Erbe unserer freien Nationen sowie der Ursprung der Menschenrechte und des Rechtsstaates sind, welche die Grundlage der Demokratie darstellen.

Uns verbindet die Überzeugung, dass die Achtung der Menschenrechte und der grundlegenden Freiheiten ein notwendiger Faktor ist, der dem Frieden, der Gerechtigkeit, der Stabilität auf der ganzen Welt förderlich ist.

Wir drücken unseren Einspruch gegenüber jeglichen Erscheinungen von Hass und jedweder Form von Diskriminierung aus. Wir verurteilen alle damit verbundenen Gewaltakte.

Wir erinnern an die tragische Geschichte unseres Kontinents und bringen unsere Überzeugung zum Ausdruck, dass die Annexion der Krim das Fundament der politisch-rechtlichen Ordnung in Europa verletzt und das Funktionieren des gesamten internationalen Systems erschüttert. Ein wirksames Mittel, Frieden und Sicherheit zu erlangen, sollten gutnachbarliche Beziehungen zwischen den Nationen und Staaten sein, gestützt auf die Prinzipien des internationalen Rechtes, insbesondere der Souveränität, der territorialen Integrität und der politischen Unabhängigkeit der Staaten.

Uns verbindet die Hoffnung auf Erweiterung des Raumes der Freiheit und Solidarität in den Beziehungen zwischen den Menschen und den Nationen.

Warschau, im Juni 2014.

Übersetzung aus dem Polnischen: Silke Plate

Anm.: Die Warschauer Freiheitserklärung wurde am 4. Juni 2014 während der zentralen Gedenkfeier anlässlich des 25. Jahrestages des Wahlsieges der Solidarność auf dem Schlossplatz in Warschau verlesen.

Polnische Version unter: <http://www.prezydent.pl/aktualnosci/wydarzenia/art,2947,warszawska-deklaracja-wolnosci.html> (abgerufen am 29.08.2014).

UMFRAGE

\section{Meinungen zu 1989}

Grafik 1: Wie beurteilen Sie die Epoche der Volksrepublik Polen in der polnischen Geschichte? (\%)

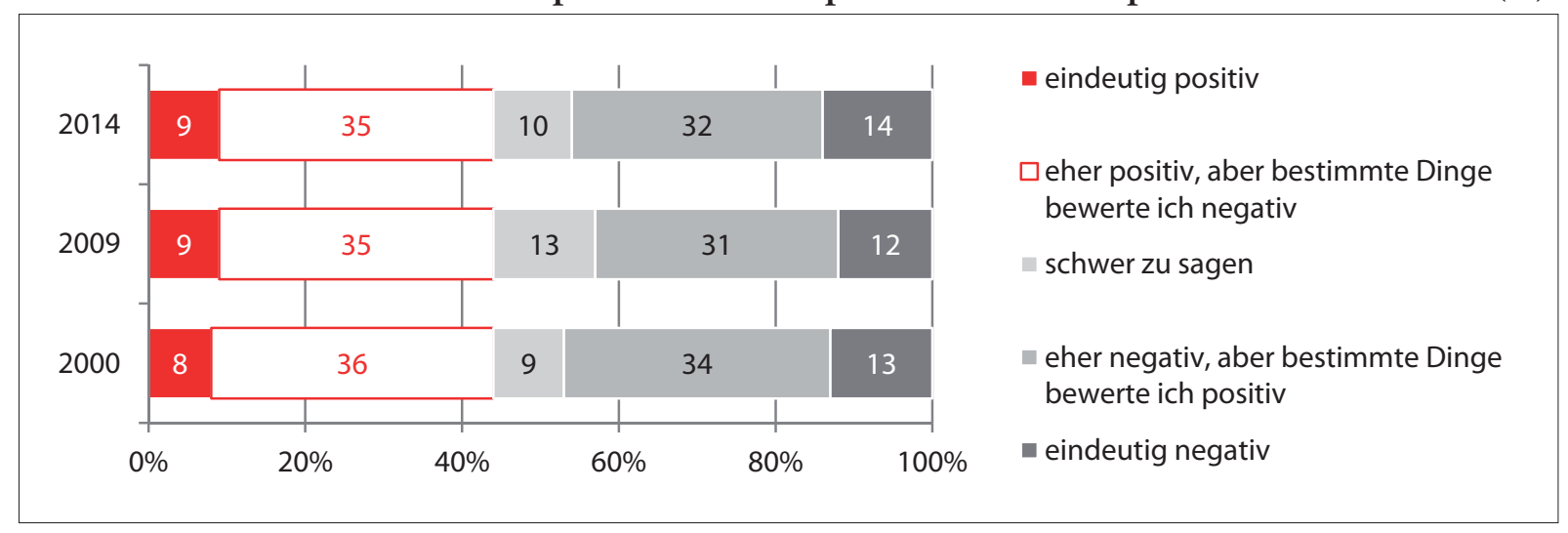

Quelle: CBOS Nr 61/2014: PRL - doświadczenie, oceny, skojarzenia [Die VR Polen - Erfahrungen, Bewertungen, Assoziationen]. Warszawa 05/2014. <www.cbos.pl> 
Grafik 2: Wie beurteilen Sie die Epoche der Volksrepublik Polen in der polnischen Geschichte? (\%)

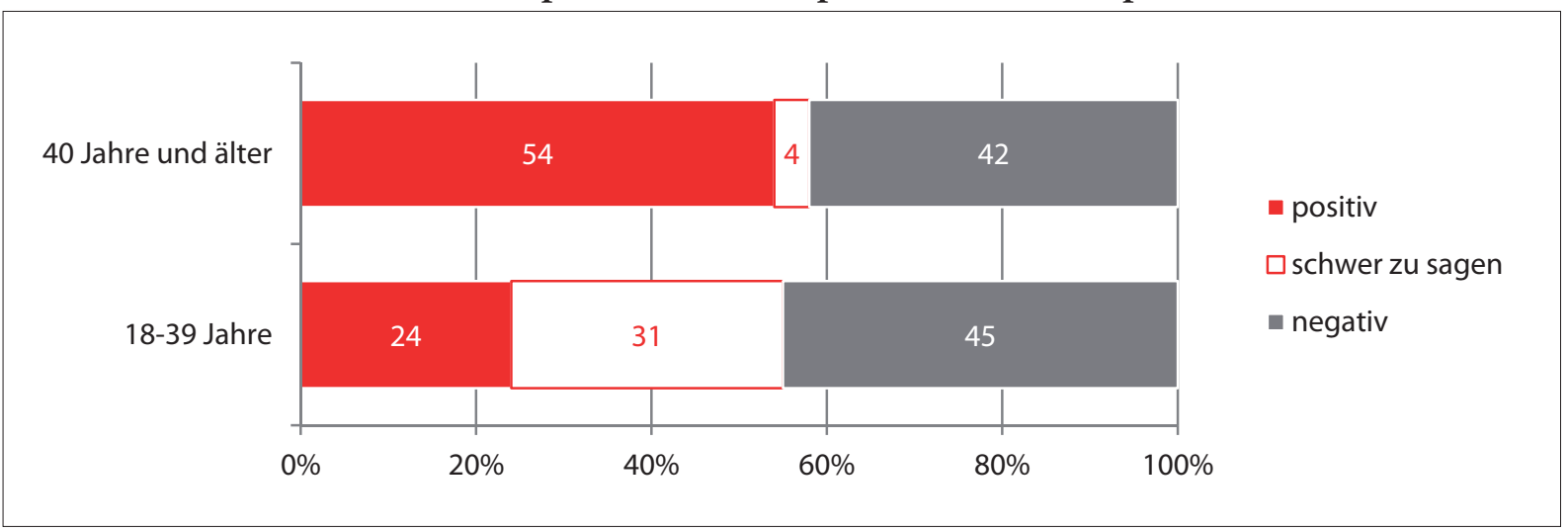

Quelle: CBOS Nr 61/2014: PRL - doświadczenie, oceny, skojarzenia [Die VR Polen - Erfahrungen, Bewertungen, Assoziationen]. Warszawa 05/2014. <www.cbos.pl>

Grafik 3: Wie beurteilen Sie die Epoche der Volksrepublik Polen in der polnischen Geschichte? (\%)

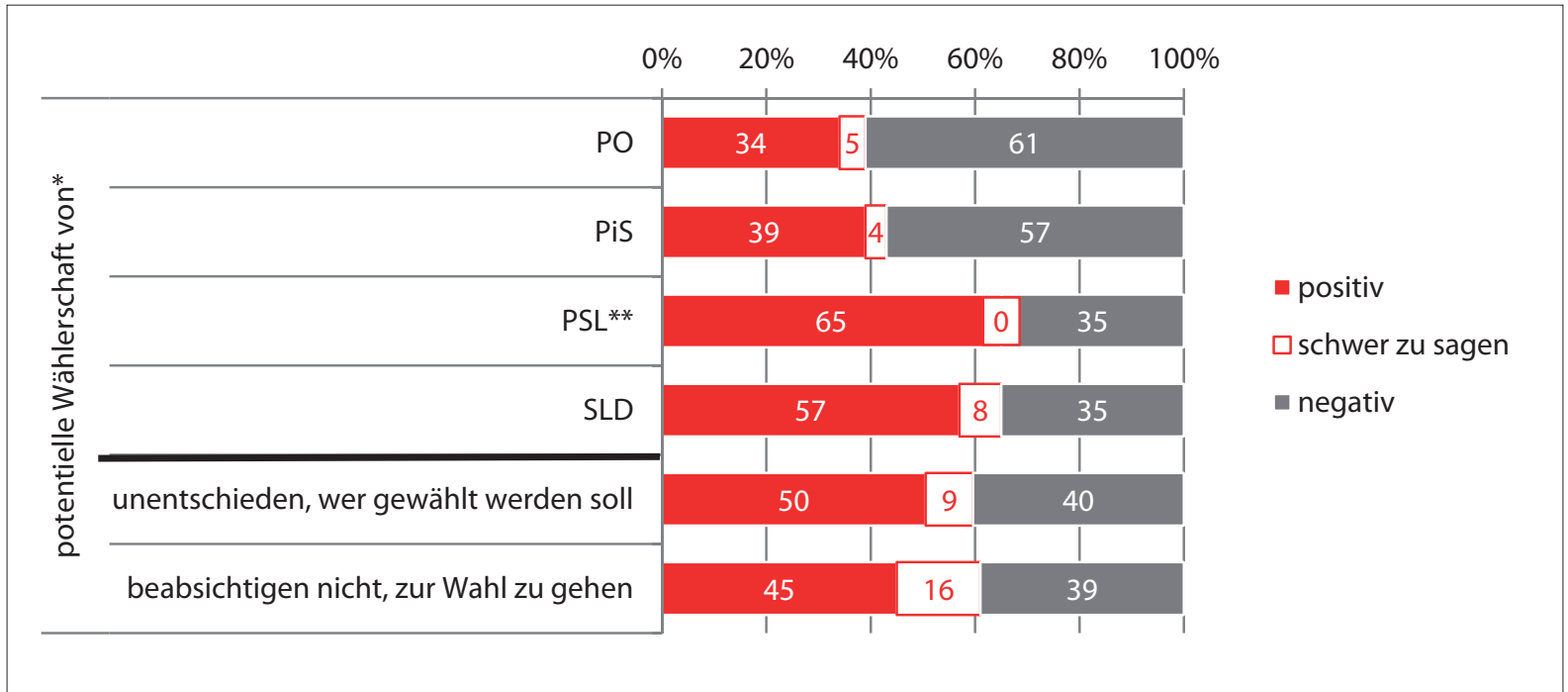

* auf der Grundlage der Erklärung bestimmt, bei potentiellen Parlamentswablen wählen zu gehen

** Die Angaben der Wähler dieser Partei gilt es aufgrund der geringen Anzahl der Wähler in der untersuchten Probe vorsichtig zu behandeln. PO - Platforma Obywatelska/Bürgerplattform

PiS - Prawo i Sprawiedliwość/Recht und Gerechtigkeit

PSL - Polskie Stronnictwo Ludowe/Polnische Bauernpartei

SLD - Sojusz Lewicy Demokratycznej/Demokratische Linksallianz

Quelle: CBOS Nr 61/2014: PRL - doświadczenie, oceny, skojarzenia [Die VR Polen - Erfahrungen, Bewertungen, Assoziationen]. Warszawa 05/2014. <www.cbos.pl> 
Grafik 4: War die Volksrepublik Polen Ihrer Meinung nach ein unabhängiges Land? (\%)

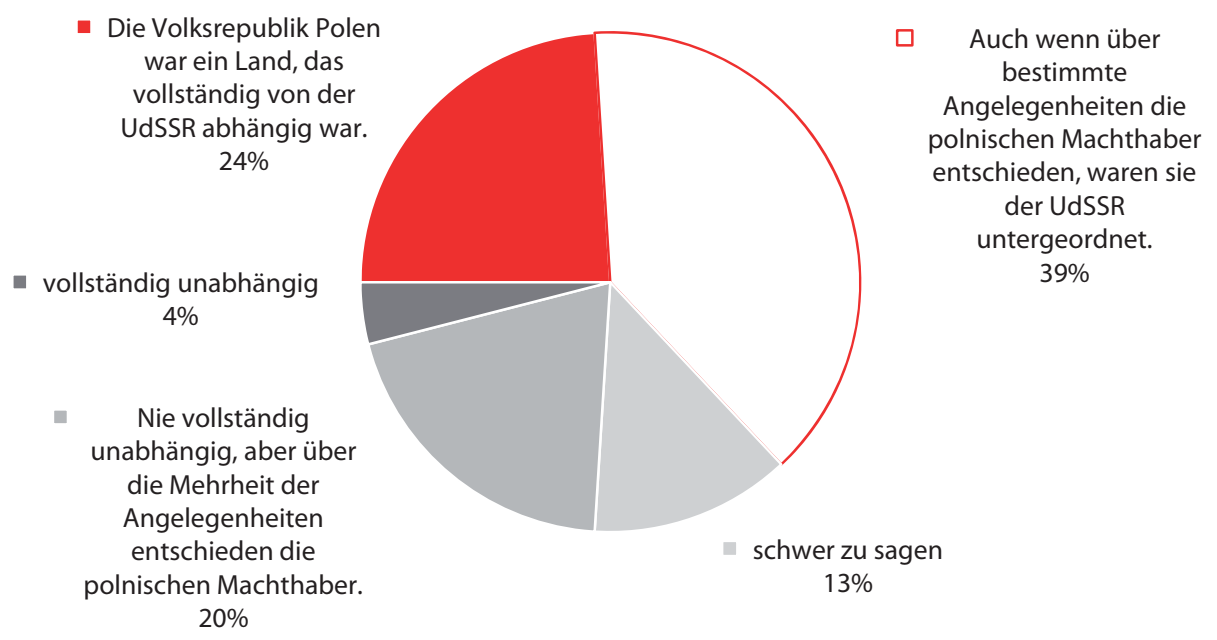

Quelle: CBOS Nr 61/2014: PRL - doświadczenie, oceny, skojarzenia [Die VR Polen - Erfahrungen, Bewertungen, Assoziationen]. Warszawa 05/2014. <www.cbos.pl>

Grafik 5: Ist für Menschen wie Sie ein besseres Land zum Leben... (\%)

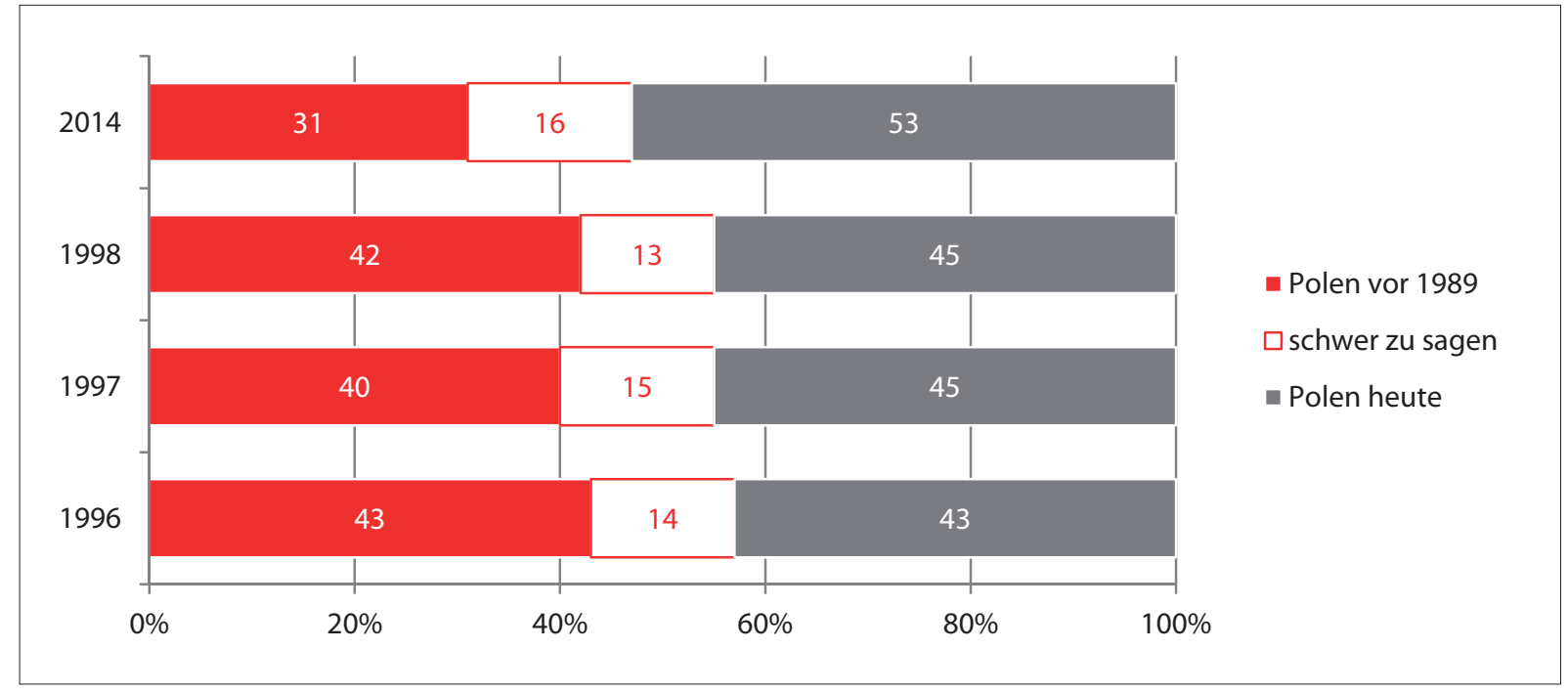

Quelle: CBOS Nr 61/2014: PRL - doświadczenie, oceny, skojarzenia [Die VR Polen - Erfahrungen, Bewertungen, Assoziationen]. Warszawa 05/2014. <www.cbos.pl> 
Grafik 6: Haben die Veränderungen, die in Polen seit 1989 eintraten, den Menschen mehr Vorteile oder mehr Einbußen gebracht?

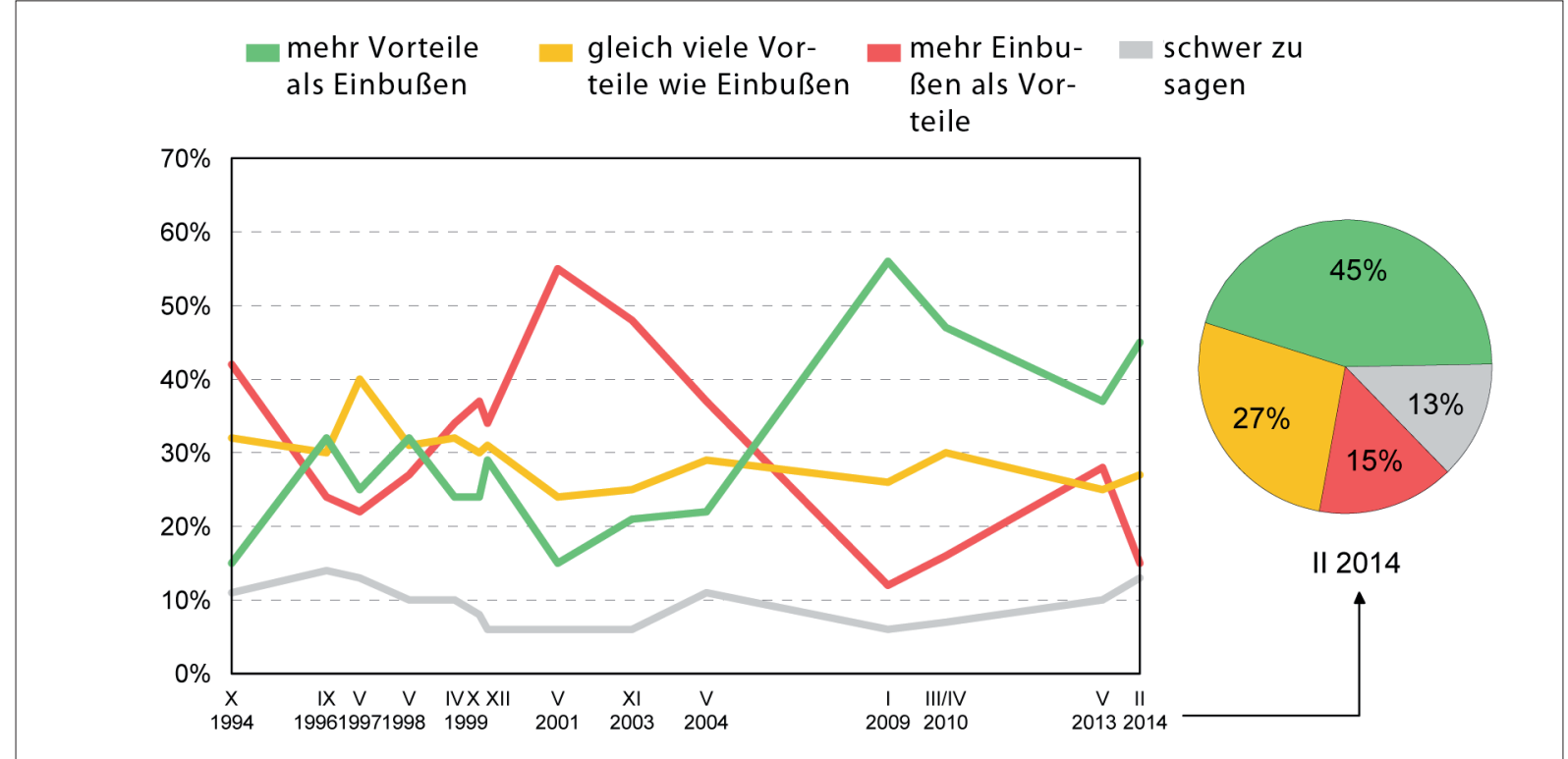

Quelle: CBOS Nr 67/2014: Czy warto byto zmieniać ustrój? Ocena zmian ustrojowych po 25 latach [Lohnte es sich, das System zu verändern? Die Bewertung der Systemveränderungen nach 25 Jahren]. Warszawa 05/2014. <www.cbos.pl>

Grafik 7: Man hört unterschiedliche Meinungen über die Folgen der Veränderungen in Polen. Wenn Sie Ihre Situation und die Ihrer Angehörigen benennen sollten, würden Sie sich dann zu denen zählen, die... (\%)

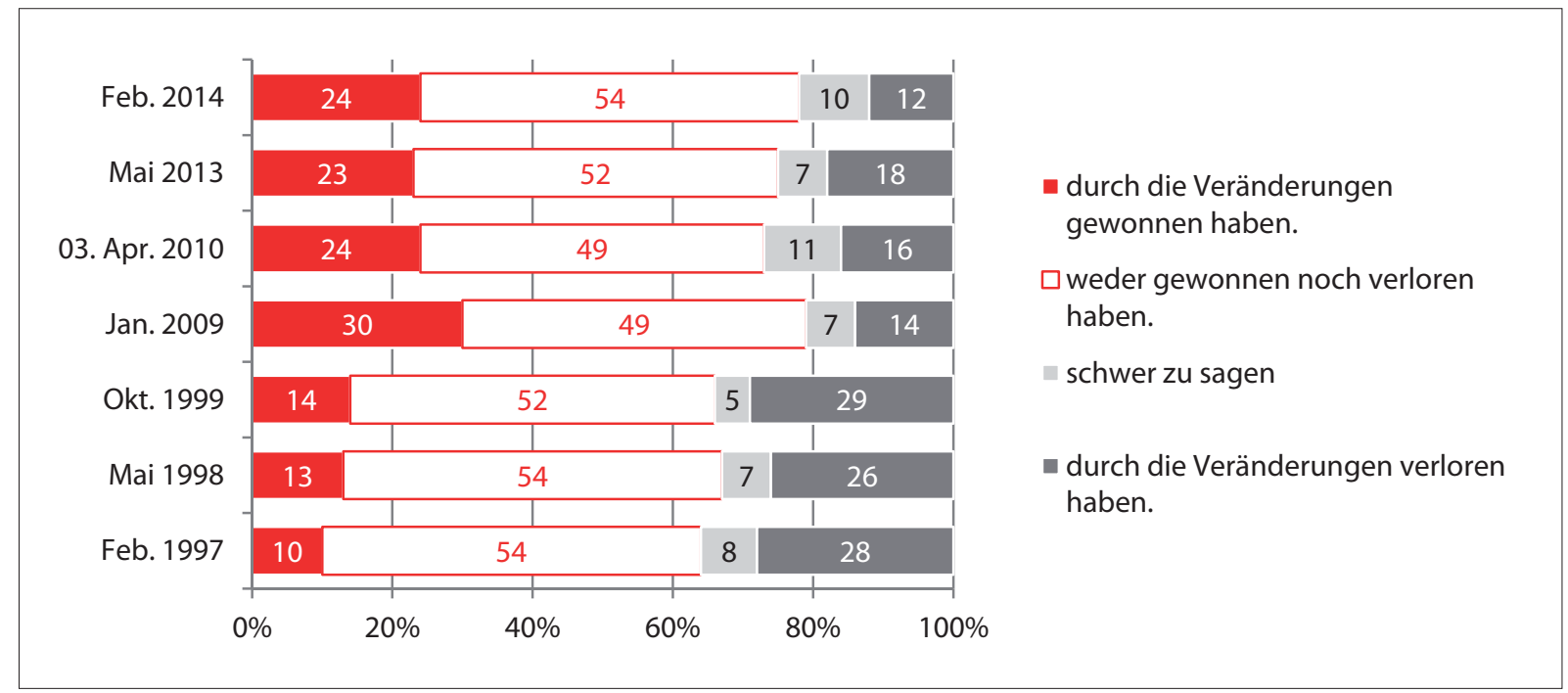

Quelle: CBOS Nr 67/2014: Czy warto byto zmieniać ustrój? Ocena zmian ustrojowych po 25 latach [Lohnte es sich, das System zu verändern? Die Bewertung der Systemveränderungen nach 25 Jahren]. Warszawa 05/2014. <www.cbos.pl> 
Grafik 8: Können Sie mit zeitlichem Abstand sagen, dass sich die Kosten der Systemtransformation in Polen nach 1989 im Verhältnis zu den Ergebnissen als... erwiesen haben? (\%)

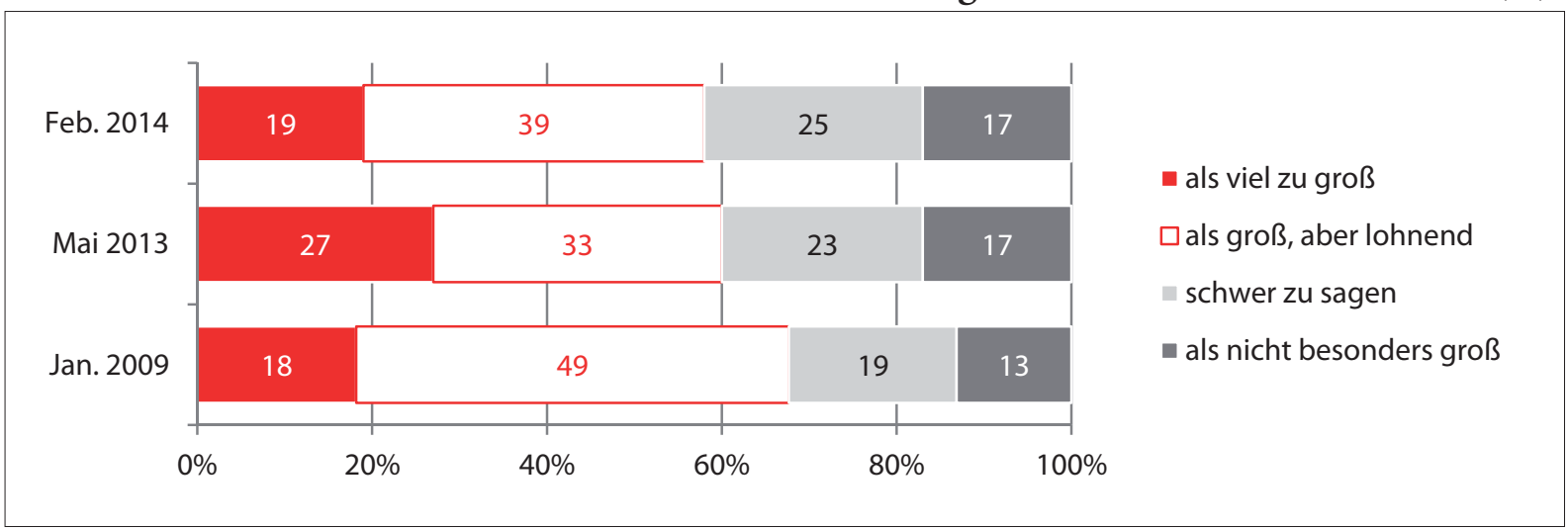

Quelle: CBOS Nr 67/2014: Czy warto było zmieniać ustrój? Ocena zmian ustrojowych po 25 latach [Lohnte es sich, das System zu verändern? Die Bewertung der Systemveränderungen nach 25 Jahren]. Warszawa 05/2014. <www.cbos.pl>

Tabelle 1: Welche Fehler, Unterlassungen wurden in der Zeit der Transformation nach 1989 begangen? (\%)

\begin{tabular}{|c|c|c|}
\hline & $\begin{array}{l}\text { Für Menschen wie Sie war Polen vor } \\
1989 \text { das bessere Land zum Leben. }\end{array}$ & $\begin{array}{c}\text { Für Menschen wie Sie ist Polen heute das } \\
\text { bessere Land zum Leben. }\end{array}$ \\
\hline $\begin{array}{l}\text { zu weit gehende Privatisierung der pol- } \\
\text { nischen Wirtschaft, das Staatseigentum } \\
\text { wurde zu einem Spottpreis verkauft }\end{array}$ & 43 & 33 \\
\hline $\begin{array}{l}\text { die Tolerierung von Korruption und } \\
\text { Unehrlichkeit in der Politik }\end{array}$ & 31 & 34 \\
\hline $\begin{array}{l}\text { es fehlte eine ausreichende Über- } \\
\text { prüfung und Abrechnung mit den } \\
\text { Mitarbeitern der Geheimdienste der } \\
\text { Volksrepublik Polen }\end{array}$ & 23 & 36 \\
\hline $\begin{array}{l}\text { es fehlte die „Dekommunisierung“ und } \\
\text { die Abrechnung mit den Staats- und } \\
\text { Parteifunktionären aus der Zeit der } \\
\text { Volksrepublik Polen }\end{array}$ & 21 & 30 \\
\hline $\begin{array}{l}\text { das Zulassen eines übermäßigen An- } \\
\text { stiegs der sozialen Ungleichheit }\end{array}$ & 24 & 22 \\
\hline $\begin{array}{l}\text { Übernahme des staatlichen Eigentums } \\
\text { durch Staats- und Parteiaktivisten }\end{array}$ & 18 & 24 \\
\hline $\begin{array}{l}\text { ein zu schnelles Tempo und ein zu } \\
\text { großer Wirkungsbereich bei den Wirt- } \\
\text { schaftsreformen }\end{array}$ & 18 & 11 \\
\hline $\begin{array}{l}\text { eine zu große Abhängigkeit vom } \\
\text { Westen }\end{array}$ & 13 & 10 \\
\hline $\begin{array}{l}\text { ein zu großer Einfluss der Kirche auf } \\
\text { die Angelegenheiten des Landes }\end{array}$ & 13 & 9 \\
\hline $\begin{array}{l}\text { Zerfall und Konflikte im Solidarność- } \\
\text { Lager }\end{array}$ & 6 & 12 \\
\hline $\begin{array}{l}\text { eine zu starke Beschränkung der } \\
\text { Rolle des Staates in der Wirtschaft und } \\
\text { anderen Lebensbereichen }\end{array}$ & 5 & 5 \\
\hline andere Fehler & 3 & 1 \\
\hline $\begin{array}{l}\text { es wurden keine wichtigeren Fehler } \\
\text { begangen }\end{array}$ & 2 & 2 \\
\hline schwer zu sagen & 15 & 11 \\
\hline
\end{tabular}

Anm.: Die Summen ergeben mehr als 100 Prozent, da die Befragten mehr als eine Antwort benennen konnten.

Quelle: CBOS Nr 63/2014: Upadek komunizmu i geneza przemian w pamięci zbiorowej [Der Zusammenbruch des Kommunismus und die Genese der Veränderungen im kollektiven Gedächtnis]. Warszawa 05/2014. www.cbos.pl 
Grafik 9: Können Sie mit zeitlichem Abstand sagen, dass es sich lohnte, 1989 das System in Polen zu verändern oder nicht? (\%)

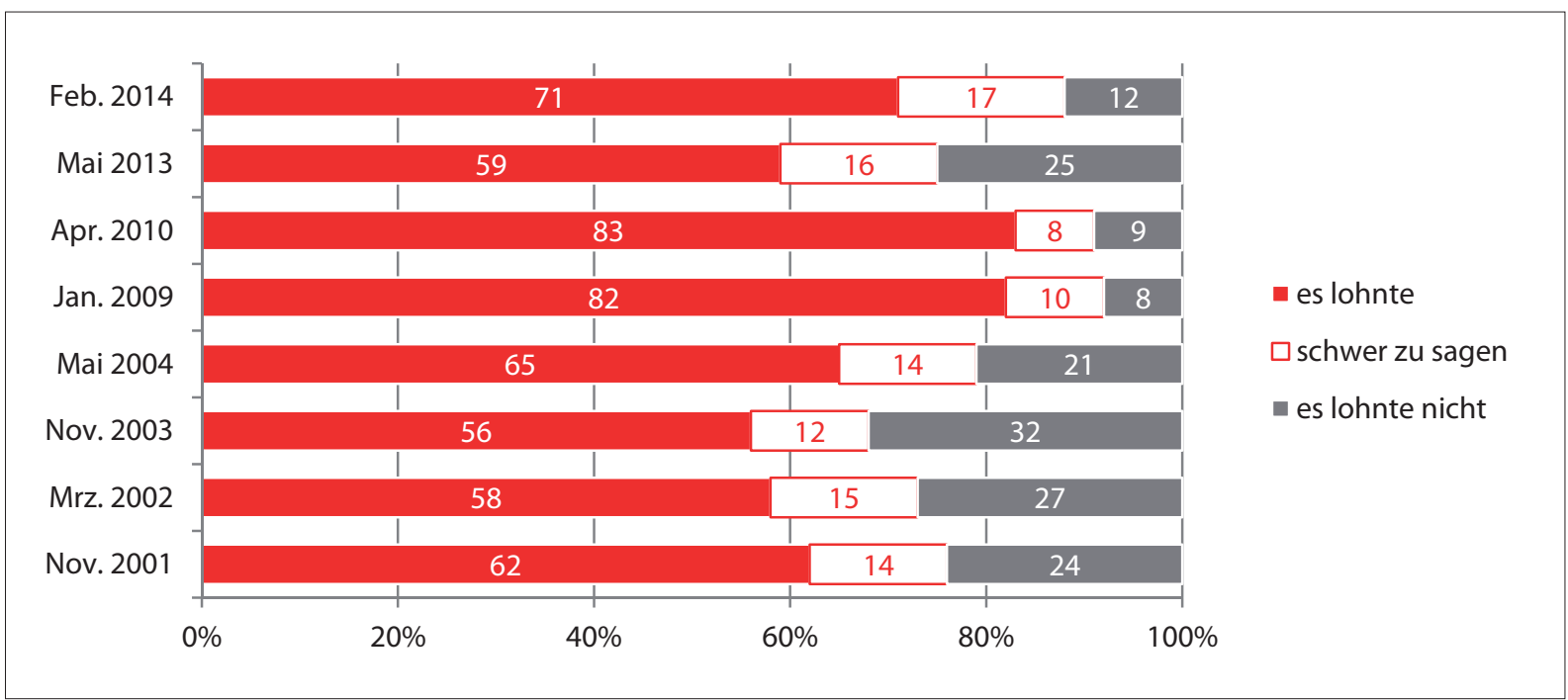

Quelle: CBOS Nr 67/2014: Czy warto byto zmieniać ustrój? Ocena zmian ustrojowych po 25 latach [Lohnte es sich, das System zu verändern? Die Bewertung der Systemveränderungen nach 25 Jahren]. Warszawa 05/2014. <www.cbos.pl>

Grafik 10: Im September 1989 entstand die Regierung mit Tadeusz Mazowiecki an der Spitze. Wie beurteilen Sie die folgenden Tätigkeiten der Regierung Mazowiecki: die Richtungsänderung in der Außenpolitik, die Öffnung nach Westen? (\%)

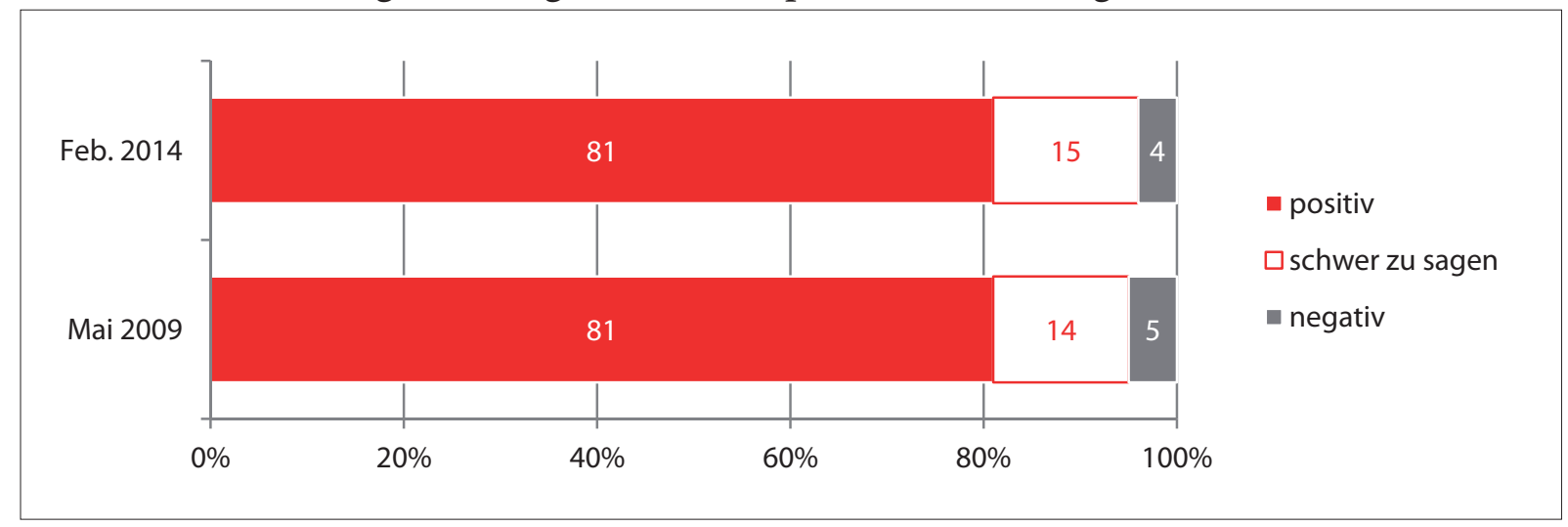

Anm.: Die Angaben zu den Antworten "positiv« bzw. "negativ« setzen sich zusammen aus "eindeutig gut» und "eher gut»bzw. "eindeutig schlecht" und "eher schlecht».

Quelle: CBOS Nr 74/2014: Wybory czerwcowe w 1989 roku i rzadd Tadeusza Mazowieckiego zperspektywy ćwierćwiecza [Die Wablen im Juni 1989 und die Regierung von Tadeusz Mazowiecki aus der Perspektive eines Vierteljahrhunderts]. Warszawa 05/2014. <www.cbos.pl> 
Grafik 11: Im September 1989 entstand die Regierung mit Tadeusz Mazowiecki an der Spitze. Wie beurteilen Sie die folgenden Tätigkeiten der Regierung Mazowiecki: die Änderung des politischen Systems, die Demokratisierung des gesellschaftlichen Lebens? (\%)

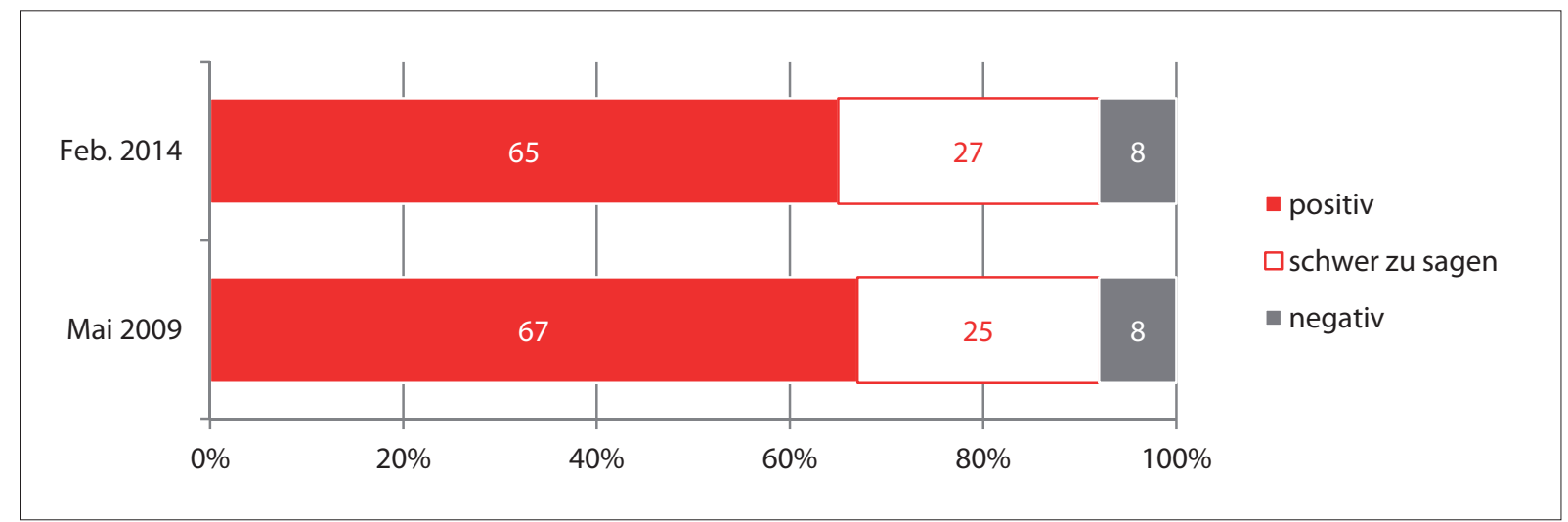

Anm.: Die Angaben zu den Antworten "positiv" bzw. "negativ" setzen sich zusammen aus "eindeutig gut" und "eher gut" bzw. "eindeutig schlecht" und "eher schlecht".

Quelle: CBOS Nr 74/2014: Wybory czerwcowew 1989 roku i rząd Tadeusza Mazowieckiego z perspektywy ćwierćwiecza [Die Wahlen im Juni 1989 und die Regierung von Tadeusz Mazowiecki aus der Perspektive eines Vierteljahrhunderts]. Warszawa 05/2014. <www.cbos.pl>

Grafik 12: Im September 1989 entstand die Regierung mit Tadeusz Mazowiecki an der Spitze. Wie beurteilen Sie die folgenden Tätigkeiten der Regierung Mazowiecki: die Einführung selbstverwalteter Gemeinden? (\%)

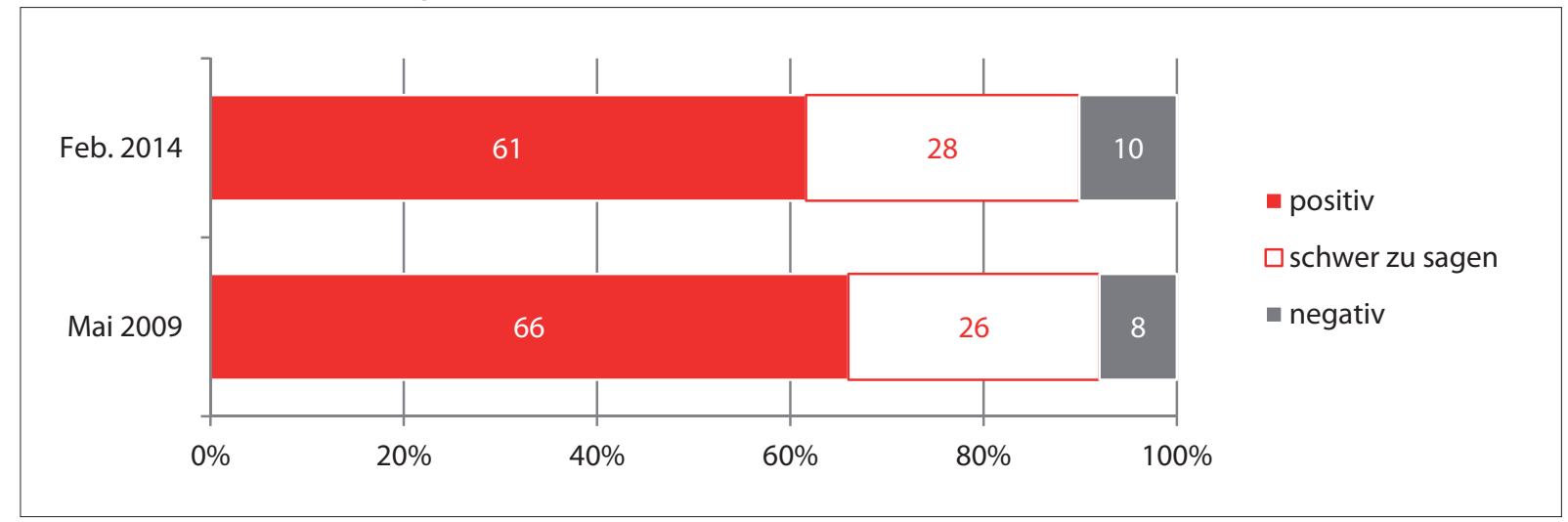

Anm.: Die Angaben zu den Antworten "positiv" bzw. "negativ" setzen sich zusammen aus "eindeutig gut" und "eher gut" bzw. "eindeutig schlecht" und "eher schlecht".

Quelle: CBOS Nr 74/2014: Wybory czerwcowe w 1989 roku i rząd Tadeusza Mazowieckiego zperspektywy ćwierćwiecza [Die Wahlen im Juni 1989 und die Regierung von Tadeusz Mazowiecki aus der Perspektive eines Vierteljahrhunderts]. Warszawa 05/2014. <www.cbos.pl> 
Grafik 13: Im September 1989 entstand die Regierung mit Tadeusz Mazowiecki an der Spitze. Wie beurteilen Sie die folgenden Tätigkeiten der Regierung Mazowiecki: die Einführung von Religion in der Schule? (\%)

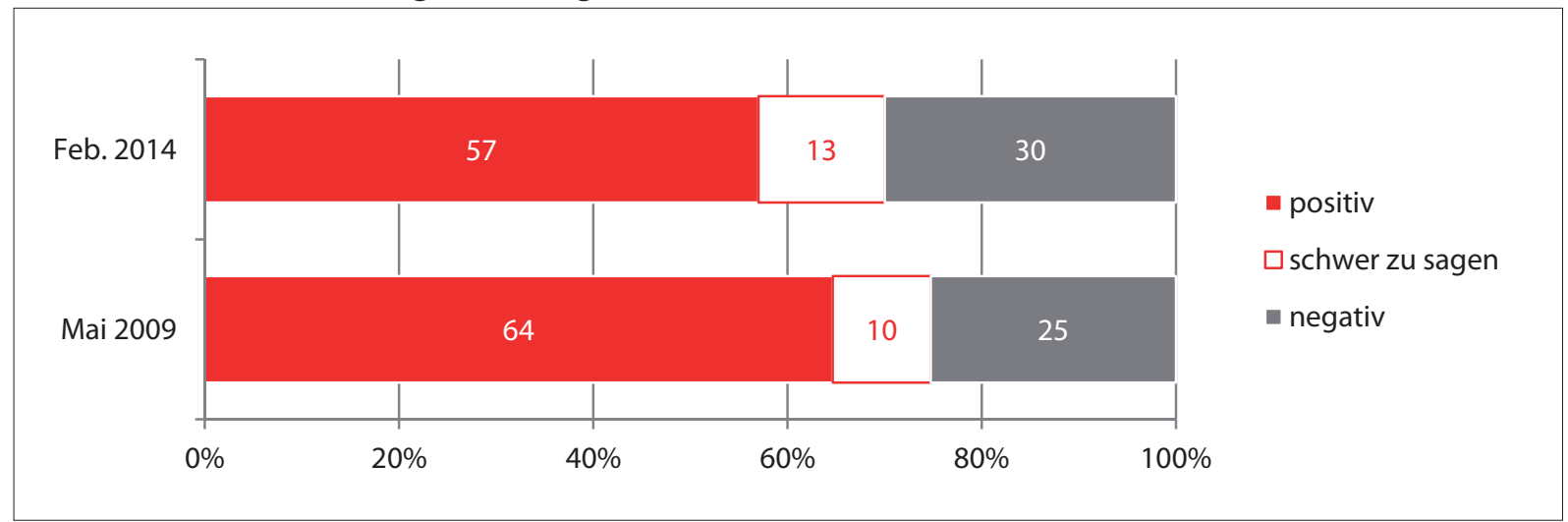

Anm.: Die Angaben zu den Antworten "positiv" bzw. "negativ" setzen sich zusammen aus "eindeutig gut" und "eher gut" bzw. "eindeutig schlecht" und "eher schlecht".

Quelle: CBOS Nr 74/2014: Wybory czerwcowe w 1989 roku i rząd Tadeusza Mazowieckiego z perspektywy ćwierćwiecza [Die Wahlen im Juni 1989 und die Regierung von Tadeusz Mazowiecki aus der Perspektive eines Vierteljahrhunderts]. Warszawa 05/2014. <www.cbos.pl>

Grafik 14: Im September 1989 entstand die Regierung mit Tadeusz Mazowiecki an der Spitze. Wie beurteilen Sie die folgenden Tätigkeiten der Regierung Mazowiecki: den Beginn der Wirtschaftsreformen, die Einführung des Balcerowicz-Plans? (\%)

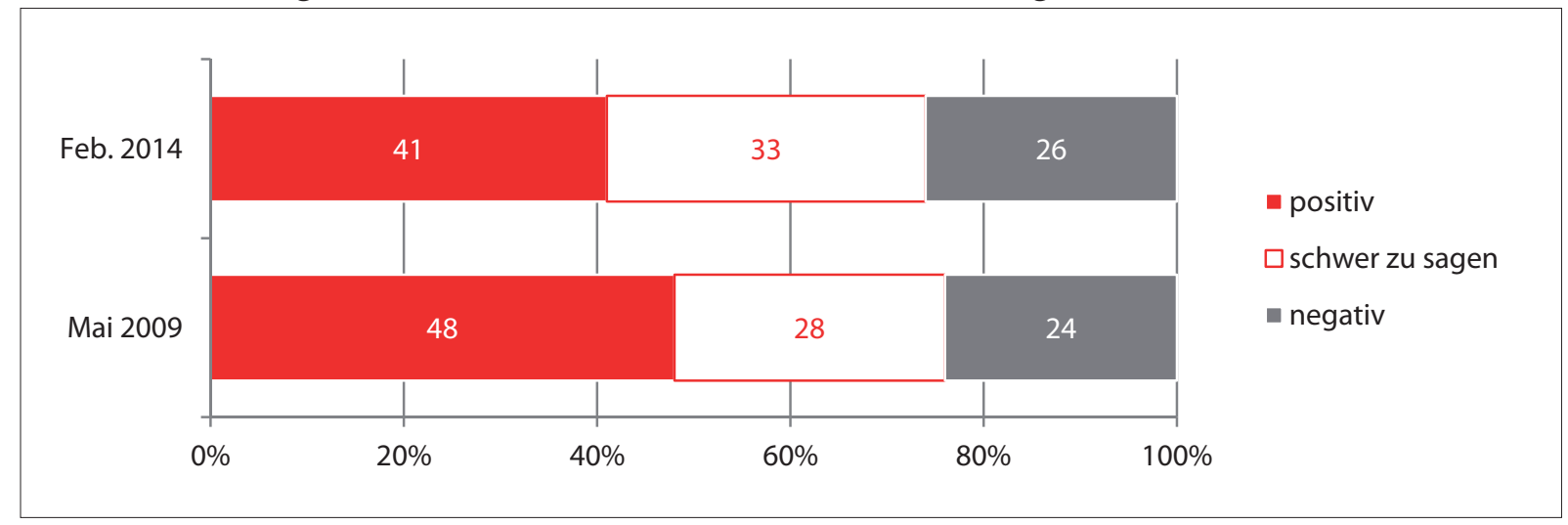

Anm.: Die Angaben zu den Antworten "positiv" bzw. "negativ" setzen sich zusammen aus "eindeutig gut" und "eher gut" bzw. "eindeutig schlecht" und "eher schlecht».

Quelle: CBOS Nr 74/2014: Wybory czerwcowe w 1989 roku i rzad Tadeusza Mazowieckiego z perspektywy ćwierćwiecza [Die Wablen im Juni 1989 und die Regierung von Tadeusz Mazowiecki aus der Perspektive eines Vierteljahrhunderts]. Warszawa 05/2014. <www.cbos.pl> 
Tabelle 2: Im September 1989 entstand die Regierung mit Tadeusz Mazowiecki an der Spitze. Wie beurteilen Sie die folgenden Tätigkeiten der Regierung Mazowiecki? (positive Antworten, \%)

\begin{tabular}{|l|c|c|c|c|c|}
\hline $\begin{array}{c}\text { erklärte Wähler } \\
\text { von: }\end{array}$ & $\begin{array}{c}\text { die Öffnung } \\
\text { nach Westen }\end{array}$ & $\begin{array}{c}\text { die Demokrati- } \\
\text { sierung }\end{array}$ & $\begin{array}{c}\text { die selbst- } \\
\text { verwalteten } \\
\text { Gemeinden }\end{array}$ & $\begin{array}{c}\text { den Balcerowicz- } \\
\text { Plan }\end{array}$ & $\begin{array}{c}\text { Einführung von } \\
\text { Religion in der } \\
\text { Schule }\end{array}$ \\
\hline PO & 93 & 84 & 83 & 63 & 49 \\
PSL & 96 & 80 & 77 & 54 & 65 \\
\hline PiS & 84 & 65 & 67 & 39 & 78 \\
\hline SLD & 91 & 88 & 70 & 44 & 42 \\
\hline Deine Bewegung & 94 & 94 & 83 & 55 & 57 \\
\hline unentschiedene & 77 & 61 & 59 & 41 & 57 \\
\hline Wähler & 74 & 57 & 50 & 32 & \\
\hline Nicht-Wähler & & & & & 57 \\
\hline
\end{tabular}

PO - Platforma Obywatelska/Bürgerplattform

PSL - Polskie Stronnictwo Ludowe/Polnische Bauernpartei

PiS - Prawo i SprawiedliwośćlRecht und Gerechtigkeit

SLD - Sojusz Lewicy Demokratycznej/Demokratische Linksallianz

Deine Bewegung/Twój Ruch

Quelle: CBOS Nr 74/2014: Wybory czerwcowe w 1989 roku i rząd Tadeusza Mazowieckiego zperspektywy ćwierćwiecza [Die Wablen im Juni 1989 und die Regierung von Tadeusz Mazowiecki aus der Perspektive eines Vierteljahrhunderts]. Warszawa 05/2014. <www.cbos.pl>

\section{CHRONIK}

\section{Juli - 1. September 2014}

\begin{tabular}{|l|l|}
\hline 01.07.2014 & $\begin{array}{l}\text { Aus Anlass des zehnjährigen Bestehens der Operativen Führung der polnischen Streitkräfte hebt Staatspräsi- } \\
\text { dent Bronisław Komorowski den Wert der in militärischen Auslandseinsätzen gewonnenen Erfahrungen für die } \\
\text { Verteidigung Polens hervor. Komorowski kündigt einen Gesetzesentwurf an, in dem die Führung der Verteidi- } \\
\text { gung, die Kompetenzen des Oberbefehlshabers im Kriegsfalle sowie der Kriegsfall selbst definiert werden. Für } \\
\text { die Akzentverschiebung auf die Verteidigung des eigenen Territoriums und die Notwendigkeit, ein modernes } \\
\text { Führungssystem aufzubauen, sprächen die aktuellen Ereignisse in der Ukraine. }\end{array}$ \\
\hline 03.07.2014 & $\begin{array}{l}\text { Ministerpräsident Donald Tusk beruft Artur Radziwiłł, Unterstaatssekretär im Finanzministerium, zum Regierungs- } \\
\text { beauftragten für die Einführung des Euro. Jacek Dominik, bisheriger Amtsinhaber, ist für neue Aufgaben vorgesehen. }\end{array}$ \\
\hline 04.07 .2014 & $\begin{array}{l}\text { Der Senat gedenkt in einer Feierstunde der ersten Sitzung des ersten freigewählten Senats seit 1945. Diese fand } \\
\text { am 4. Juli 1989 statt. Vertreter des Bürgerkomitees der Solidarność hatten damals 99 von 100 Sitzen erlangt. }\end{array}$ \\
\hline 05.07.2014 & $\begin{array}{l}\text { Der Parteivorsitzende von Recht und Gerechtigkeit (Prawo i Sprawiedliwość - PiS), Jarosław Kaczyński, spricht } \\
\text { sich abermals für einen Zusammenschluss konservativer Parteien aus, mit dem Ziel, die Regierungsverantwor- } \\
\text { tung übernehmen zu können. Eine Zusammenarbeit mit Janusz Korwin-Mikke, Parteichef der Neuen Rechten } \\
\text { von Janusz Korwin-Mikke (Nowa Prawica Janusza Korwin-Mikke), die bei der Wahl zum Europäischen Parla- } \\
\text { ment im Mai überraschend vier Mandate erlangte, schließt er jedoch aus. }\end{array}$ \\
\hline 06.07 .2014 & $\begin{array}{l}\text { Nach Einschätzung von Ministerpräsident Donald Tusk auf einer Vorstandssitzung der Bürgerplattform (Plat- } \\
\text { forma Obywatelska - PO) sollte die sogenannte Abhöraffäre dazu dienen, die Lage in Polen zu destabilisieren. Es } \\
\text { gebe sehr viele illegale Gesprächsmitschnitte, die an verschiedenen Orten sowohl von Vertretern der Regierung } \\
\text { als auch der Opposition und der Wirtschaft aufgenommen wurden. Ein Teil der Gespräche wurde im Wochen- } \\
\text { magazin »Wprost«ab Mitte Juni veröffentlicht. }\end{array}$ \\
\hline
\end{tabular}




\begin{tabular}{|c|c|}
\hline 07.07.2014 & $\begin{array}{l}\text { Bei einem Spitzentreffen thematisieren führende Politiker der Regierungskoalition aus Bürgerplattform (Plat- } \\
\text { forma Obywatelska-PO) und Polnischer Bauernpartei (Polskie Stronnictwo Ludowe-PSL) das für diese Woche } \\
\text { anberaumte, von Recht und Gerechtigkeit (Prawo i Sprawiedliwość - PiS) beantragte konstruktive Misstrau- } \\
\text { ensvotum sowie die Rücktrittsforderung von PiS an Innenminister Bartłomiej Sienkiewicz. Nach dem Treffen } \\
\text { bekräftigt PO-Generalsekretär Paweł Graś die Stabilität der Regierung und der Koalition nach dem gescheiter- } \\
\text { ten Misstrauensvotum in der vergangenen Woche. Der Fraktionschef der PO, Rafał Grupiński, gab als gemein- } \\
\text { same Handlungsstrategie die Verteidigung der Regierung aus. Hintergrund der Krise sind von der Wochenzei- } \\
\text { tung "Wprost« veröffentlichte illegal mitgeschnittene Gespräch zwischen Regierungsmitgliedern und Personen } \\
\text { aus dem politischen Umfeld. }\end{array}$ \\
\hline 08.07.2014 & $\begin{array}{l}\text { In einem Radiointerview zeigt sich Zbigniew Ziobro, Parteivorsitzender von Solidarisches Polen von Zbigniew } \\
\text { Ziobro (Solidarna Polska Zbigniewa Ziobra), offen für weitere Gespräche mit Jaroslaw Kaczyński, Parteichef } \\
\text { von Recht und Gerechtigkeit (Prawo i Sprawiedliwość - PiS), über ein Bündnis beider Parteien mit dem Ziel, } \\
\text { die Regierung aus Bürgerplattform (Platforma Obywatelska - PO) und Polnischer Bauernpartei (Polskie Stron- } \\
\text { nictwo Ludowe - PSL) abzulösen. Er sei dann bereit, PiS als im Bündnis dominierenden Partner anzuerkennen. } \\
\text { Bedingung sei jedoch ein schriftlicher Vertrag über das Bündnis, so Ziobro. }\end{array}$ \\
\hline 09.07.2014 & $\begin{array}{l}\text { Die Europäische Kommission fordert von Polen eine Rückerstattung in Höhe von 5,84 Mio. Euro aus dem Fonds } \\
\text { zur Entwicklung des ländlichen Raums. Insgesamt fordert die Europäische Kommission } 57 \text { Mio. Euro von } 15 \\
\text { EU-Ländern zurück. Begründet werden die Rückforderungen damit, dass die Vorschriften nicht eingehalten } \\
\text { oder keine angemessenen Kontrollen der Ausgaben durchgeführt worden seien. Landwirtschaftsminister Marek } \\
\text { Sawicki kündigt im Falle Polens Einspruch gegen die Entscheidung der EU-Kommission an. }\end{array}$ \\
\hline 10.07 .2014 & $\begin{array}{l}\text { Die Europäische Kommission verklagt Polen vor dem Europäischen Gerichtshof in Straßburg wegen nicht erfolg- } \\
\text { ter Umsetzung der Richtlinie über das Energieprofil von Gebäuden, die im Juli } 2012 \text { in nationales Recht über- } \\
\text { nommen worden ist. Bis zur Urteilsverkündung schlägt die Kommission eine Strafe in Tagessätzen à } 96.720 \text { Euro } \\
\text { vor. Der Gerichtshof wird die endgültige Summe festlegen. }\end{array}$ \\
\hline 11.07.2014 & $\begin{array}{l}\text { Der Sejm lehnt den Antrag auf ein konstruktives Misstrauensvotum gegenüber der Regierung mit } 236 \text { Stimmen } \\
\text { zu } 155 \text { Stimmen ( } 60 \text { Enthaltungen) ab. Gegen den Antrag auf ein Misstrauensvotum gegenüber Innenminis- } \\
\text { ter Bartłomiej Sienkiewicz sprechen sich } 235 \text { Abgeordnete bei } 213 \text { Ja-Stimmen und einer Enthaltung aus. Die } \\
\text { Anträge waren von Recht und Gerechtigkeit (Prawo i Sprawiedliwość - PiS) initiiert worden. Hintergrund ist } \\
\text { die Veröffentlichung von illegal mitgeschnittenen Gesprächen von Politikern und weiteren hohen Funktionsträ- } \\
\text { gern in der Wochenzeitung "Wprost«. }\end{array}$ \\
\hline 12.07 .2014 & $\begin{array}{l}\text { Die Vorsitzenden von Solidarisches Polen (Solidarna Polska) und Polen Gemeinsam (Polska Razem), Zbigniew } \\
\text { Ziobro und Jarosław Gowin, informieren, dass sie einen Brief an die Teilnehmer der Versammlung konservati- } \\
\text { ver Gruppierungen gerichtet hätten, an der sie auf Einladung von Recht und Gerechtigkeit (Prawo i Sprawied- } \\
\text { liwość - PiS) teilgenommen haben. Neben der gemeinsamen Überzeugung, dass die Regierung aus PO und } \\
\text { PSL mit Hilfe der vereinigten konservativen und patriotischen Kräfte des Amtes enthoben werden sollte, wur- } \\
\text { den programmatische Bedingungen für die Zusammenarbeit der konservativen Kräfte formuliert, vor allem im } \\
\text { Bereich Wirtschaft und Finanzen. }\end{array}$ \\
\hline 15.07.2014 & $\begin{array}{l}\text { Der Staatspräsident der Slowakei, Andrej Kiska, trifft zu einem offiziellen Besuch in Polen ein. Staatspräsident } \\
\text { Bronisław Komorowski und Kiska heben die positiven polnisch-slowakischen Beziehungen hervor und sprechen } \\
\text { sich für eine verstärkte Zusammenarbeit aus. }\end{array}$ \\
\hline 16.07 .2014 & $\begin{array}{l}\text { Nach aktuellen Angaben des Statistischen Hauptamtes (Główny Urząd Statystyczny - GUS) betrug der durch- } \\
\text { schnittliche Monatslohn im Unternehmenssektor im Juni 3.943,01 Zloty (ca. } 940 \text { Euro). }\end{array}$ \\
\hline 18.07.2014 & $\begin{array}{l}\text { Dem Sejm wird ein Bürgergesetzesentwurf zur Anerkennung der Schlesier als ethnische Gruppe vorgelegt. Jerzy } \\
\text { Gorzelik, Vorsitzender der Bewegung für ein Autonomes Schlesien (Ruch Autonomii Śląska - RAŚ), warnt, dass } \\
\text { infolge der aktuellen Rechtslage die schlesische Identität von dem Aussterben bedroht sei, da die Kinder in der } \\
\text { Region nichts über die Geschichte und das kulturelle Erbe Oberschlesiens lernen würden. Dies würde langfris- } \\
\text { tig zu einer Form von Entwurzelung führen. Für die Vorlage eines Bürgergesetzesentwurfs müssen mindestens } \\
100.000 \text { Unterschriften vorgelegt werden; in diesem Fall wurden } 140.000 \text { gesammelt. }\end{array}$ \\
\hline
\end{tabular}




\begin{tabular}{|c|c|}
\hline 19.07.2014 & $\begin{array}{l}\text { Die Parteivorsitzenden von Recht und Gerechtigkeit (Prawo i Sprawiedliwość - PiS), Solidarisches Polen (Soli- } \\
\text { darna Polska) und Polen Gemeinsam (Polska Razem), Jarosław Kaczyński, Zbigniew Ziobro und Jarosław Gowin, } \\
\text { unterzeichnen eine Vereinbarung über die Nominierung eines gemeinsamen Kandidaten für die kommenden } \\
\text { Präsidentschaftswahlen sowie über gemeinsame Kandidaten für die Selbstverwaltungs- und Parlamentswahlen } \\
\text { auf der Wahlliste von PiS. Außerdem wird die solidarische Zusammenarbeit im Sejm, Senat und anderen Gre- } \\
\text { mien festgelegt. Ziel der drei Parteien ist es, eine starke Alternative zur Regierungskoalition aus Bürgerplattform } \\
\text { (Platforma Obywatelska - PO) und Polnischer Bauernpartei (Polskie Stronnictwo Ludowe - PSL) zu stellen, die } \\
\text { nach Ansicht der Unterzeichner ihr Regierungsmandat verloren habe. }\end{array}$ \\
\hline 21.07.2014 & $\begin{array}{l}\text { Nach Angaben des Finanzministeriums beliefen sich die Transferleistungen der EU nach Polen im Juni } 2014 \\
\text { auf ca. 1,1 Mrd. Euro, das sind ca. } 702 \text { Mio. Euro im Rahmen der Kohäsionspolitik und ca. } 397 \text { Mio. Euro im } \\
\text { Bereich der Gemeinsamen Agrarpolitik. Im selben Zeitraum zahlte Polen ca. } 316 \text { Mio. Euro in das EU-Bud- } \\
\text { get ein. Seit Jahresanfang } 2014 \text { betrug der Transfer aus der EU nach Polen } 10 \text { Mrd. Euro, in umgekehrter Rich- } \\
\text { tung 2,67 Mrd. Euro. }\end{array}$ \\
\hline 22.07 .2014 & $\begin{array}{l}\text { Auf Einladung von Staatspräsident Bronisław Komorowski treffen sich in Warschau die Staatspräsidenten der } \\
\text { baltischen Staaten, der Visegrád-Gruppe, Rumäniens und Bulgariens. Hauptthema ist der NATO-Gipfel im } \\
\text { Herbst in Wales. Komorowski bewertet den russisch-ukrainischen Konflikt als die größte Herausforderung für die } \\
\text { Sicherheit Europas seit dem Ende des Kalten Krieges. Er spricht sich für eine Verstärkung der sog. Ostflanke der } \\
\text { NATO aus und warnt vor einer Einteilung der NATO-Mitglieder in Bündnispartner verschiedener Kategorien. }\end{array}$ \\
\hline 23.07.2014 & $\begin{array}{l}\text { Nach neuesten Angaben des Statistischen Hauptamtes (Główny Urząd Statystyczny - GUS) betrug die Arbeits- } \\
\text { losenquote im Juni } 2014 \text { 12\% (Juni 2013: 13,2\%). }\end{array}$ \\
\hline 24.07.2014 & $\begin{array}{l}\text { Der Europäische Gerichtshof für Menschenrechte in Straßburg verurteilt Polen wegen Verletzung der Europäi- } \\
\text { schen Menschenrechtskonvention. Hintergrund ist, dass Polen in den Jahren } 2002 \text { und } 2003 \text { ein CIA-Geheim- } \\
\text { gefängnis in Nordpolen unterstützt und die Folter von islamistischen Terrorverdächtigen in Kauf genommen } \\
\text { hat. Zwei der Gefangenen hatten geklagt; ihnen soll Polen eine Entschädigung zahlen. Ministerpräsident Donald } \\
\text { Tusk kündigt an, dass die Möglichkeiten der Berufung gegen das Urteil geprüft werden. }\end{array}$ \\
\hline 25.07.2014 & $\begin{array}{l}\text { Außenminister Radosław Sikorski teilt mit, dass die Regierung als Reaktion auf die Rolle Moskaus im russisch- } \\
\text { ukrainischen Konflikt das für } 2015 \text { geplante »Polnisch-Russische Jahr« für lange Zeit verschiebe. }\end{array}$ \\
\hline 28.07.2014 & $\begin{array}{l}\text { In Warschau findet ein Treffen zwischen Außenminister Radosław Sikorski, Verteidigungsminister Tomasz Siemio- } \\
\text { niak und ihren britischen Amtskollegen Philip Hammond und Michael Fallon statt. Auf dem Programm stehen } \\
\text { Fragen der Sicherheit, die bilateralen Beziehungen, die Zukunft der EU und der NATO-Gipfel im Herbst in Wales. }\end{array}$ \\
\hline 29.07.2014 & $\begin{array}{l}\text { In Berlin eröffnen Bundespräsident Joachim Gauck und Staatspräsident Bronisław Komorowski die Ausstellung } \\
\text { "Der Warschauer Aufstand 1944«aus Anlass des Beginns des Warschauer Aufstands gegen die deutsche Besat- } \\
\text { zung am 1. August vor } 70 \text { Jahren. Anwesend sind auch Veteranen des Aufstands. Konzipiert wurde die Ausstel- } \\
\text { lung vom Museum des Warschauer Aufstands in Warschau. }\end{array}$ \\
\hline 30.07 .2014 & $\begin{array}{l}\text { Offiziell aus hygienischen Gründen spricht Russland ein Importverbot für polnisches Obst und Gemüse ab dem } \\
\text { 1. August aus. Die Entscheidung wurde nach der Verschärfung der Sanktionen von Seiten der EU gegenüber } \\
\text { Russland infolge des russisch-ukrainischen Konfliktes bekanntgegeben. }\end{array}$ \\
\hline 01.08 .2014 & $\begin{array}{l}\text { Auf dem Militärfriedhof des Warschauer Powązki-Friedhofes findet in Anwesenheit von Staatspräsident Bronisław } \\
\text { Komorowski, Ministerpräsident Donald Tusk, Veteranen des Warschauer Aufstands sowie weiteren Würdenträ- } \\
\text { gern die zentrale Gedenkfeier zum Warschauer Aufstand gegen die deutschen Besatzer statt, der vor } 70 \text { Jahren } \\
\text { begann und } 63 \text { Tage dauerte. }\end{array}$ \\
\hline 03.08 .2014 & $\begin{array}{l}\text { In einem Interview für den Sender CNN unterstreicht Außenminister Radosław Sikorski, dass sich Polen ange- } \\
\text { sichts der Aktivitäten Russlands in der Ostukraine weniger sicher fühle. In Polen sei die Präsenz des US-ameri- } \\
\text { kanischen Militär und der NATO gewachsen, jedoch bedürfe es weiterer Schritte zur Verstärkung der östlichen } \\
\text { Grenze der NATO. Entsprechende Entscheidungen erwarte er vom NATO-Gipfel im Herbst. }\end{array}$ \\
\hline 04.08 .2014 & $\begin{array}{l}\text { Ministerpräsident Donald Tusk, Vorsitzender der Bürgerplattform (Platforma Obywatelska-PO), beginnt eine } \\
\text { Reihe von Treffen mit führenden regionalen PO-Politikern, um den Wahlkampf für die Selbstverwaltungsor- } \\
\text { gane auf die jeweilige Region abzustimmen. Die Wahlen werden im November stattfinden. }\end{array}$ \\
\hline 05.08 .2014 & $\begin{array}{l}\text { Das Landwirtschaftsministerium teilt mit, dass aus Anlass des von Russland verhängten Importverbots für Obst } \\
\text { und Gemüse aus Polen eine Arbeitsgruppe gebildet wird, die sich mit der Stabilisierung des polnischen Obst- und } \\
\text { Gemüsemarktes befassen wird. Ihr gehören Vertreter der Ministerien für Wirtschaft, Finanzen, Staatsschatz und } \\
\text { Landwirtschaft sowie der Behörde für den Schutz der Konkurrenz und der Verbraucher an. }\end{array}$ \\
\hline
\end{tabular}




\begin{tabular}{|c|c|}
\hline 06.08 .2014 & $\begin{array}{l}\text { Die Bezirksstaatsanwaltschaft Warschau beginnt das Ermittlungsverfahren im Fall des illegal mitgeschnitte- } \\
\text { nen Gespräches zwischen Innenminister Bartłomiej Sienkiewicz und dem Präsidenten der Polnischen National- } \\
\text { bank (Narodowy Bank Polski - NBP), Marek Belka. Die sogenannte Abhöraffäre kam durch Veröffentlichun- } \\
\text { gen von Gesprächen von Politikern und anderen hohen Funktionsträgern in der Wochenzeitung "Wprost« im } \\
\text { Juni ins Rollen. }\end{array}$ \\
\hline 08.08.2014 & $\begin{array}{l}\text { Das Außenministerium gibt bekannt, dass nach Urteil des Rechtlichen Beraterkomitees beim Außenministerium } \\
\text { auf der Grundlage des internationalen Rechtes der Anschluss der ukrainischen Halbinsel Krim an das russische } \\
\text { Staatsgebiet im März als Annexion und die Krim als besetztes Gebiet bewertet werden muss. }\end{array}$ \\
\hline 11.08 .2014 & $\begin{array}{l}\text { Die EU-Kommission reduziert Polen und neun weiteren Mitgliedsstaaten die Fischfangquoten für das Jahr } 2014 \\
\text { bei den Fischbeständen, bei denen im vergangenen Jahr die Fangquoten überschritten wurden. Dies betrifft vor } \\
\text { allem die Bestände von Schellfisch, Makrele und Hering. }\end{array}$ \\
\hline 12.08 .2014 & $\begin{array}{l}\text { Die Regierung verabschiedet das "Landesprogramm für Soziale Ökonomie« und das »Programm zur Bekämp- } \\
\text { fung von Armut und sozialem Ausschluss«. Die Programme gelten für die Jahre } 2014 \text { bis } 2020 \text { und sehen u. a. die } \\
\text { Schaffung von Arbeitsplätzen und die Integration von Menschen mit Behinderungen in den Arbeitsmarkt vor. }\end{array}$ \\
\hline 13.08 .2014 & $\begin{array}{l}\text { Ministerpräsident Donald Tusk thematisiert mit Gewerkschaftsvertretern der Bergbaubranche die Zukunft des } \\
\text { Kohlesektors. Eine Arbeitsgruppe aus Regierungsvertretern, Vertretern der Kohlegesellschaften und Vertretern } \\
\text { für soziale Belange wird den Vorschlag der Gewerkschaftsvertreter prüfen, die drei Kohlekonzerne Kompania } \\
\text { Węglowa, Katowicki Holding Węglowy und Węglokoks zusammenzuschließen, so dass sie ohne Mittler Han- } \\
\text { del treiben können. }\end{array}$ \\
\hline 14.08 .2014 & $\begin{array}{l}\text { Nach dem Besuch von Landwirtschaftsminister Marek Sawicki in Minsk (Belarus) informiert das Ministerium, } \\
\text { dass eine Wirtschaftsdelegation von Obst-und Gemüseproduzenten nach Belarus fahren werde, um die Mög- } \\
\text { lichkeiten für Investitionen und einen stärkeren Handel zwischen beiden Ländern auszuloten. Belarus ist nach } \\
\text { Russland und der Ukraine der wichtigste Wirtschaftspartner Polens unter den Ländern der GUS und hat sich } \\
\text { dem russischen Embargo für westliche Lebensmittel nicht angeschlossen. }\end{array}$ \\
\hline 15.08 .2014 & $\begin{array}{l}\text { Am »Tag der Polnischen Armee« mahnt Staatspräsident Bronisław Komorowski vor dem Hintergrund des rus- } \\
\text { sisch-ukrainischen Konflikts, dass die Freiheit nie für immer gegeben sei, vielmehr müsse sie geplegt, geschätzt } \\
\text { und gestärkt werden. Polen wolle sowohl gute Beziehungen mit seinen Nachbarn einschließlich Russland als } \\
\text { auch Sicherheit. Um potentielle Aggressoren abzuschrecken, müsse Polen seine Bereitschaft demonstrieren, sei- } \\
\text { nen Staat zu verteidigen. }\end{array}$ \\
\hline 16.08 .2014 & $\begin{array}{l}\text { Der Chef des Büros für Nationale Sicherheit (Biuro Bezpieczeństwa Narodowego - BBN), General Stanisław } \\
\text { Koziej, unterstreicht in einem Radiointerview, dass sich Polen seit einigen Monaten bemüht, den Ostflügel der } \\
\text { NATO zu stärken. Entscheidungen u. a. zu einer logistischen Basis auf dem Territorium Polens und der balti- } \\
\text { schen Staaten seien auf dem NATO-Gipfel im September zu erwarten. }\end{array}$ \\
\hline 19.08.2014 & $\begin{array}{l}\text { Der Fraktionsvorsitzende von Recht und Gerechtigkeit (Prawo i Sprawiedliwość - PiS), Mariusz Błaszczak, for- } \\
\text { dert von der Regierung Anstrengungen mit dem Ziel, Russland im Zusammenhang mit dem russisch-ukrai- } \\
\text { nischen Konflikt aus internationalen Gremien wie dem Europarat in Straßburg auszuschließen. Neben wirt- } \\
\text { schaftlichen Sanktionen müssten auch politische Sanktionen gegen Russland verhängt werden. Die Tatsache, } \\
\text { dass Polen beim Treffen der Außenminister von Deutschland, Frankreich, der Ukraine und Russland am ver- } \\
\text { gangenen Wochenende in Berlin nicht vertreten gewesen sei, zeige, dass Deutschland die Verbindungsposition } \\
\text { zwischen der Ukraine und der EU eingenommen habe und Polen auf der internationalen Bühne isoliert sei. Die } \\
\text { Außenpolitik der Regierung sei gescheitert. }\end{array}$ \\
\hline 20.08.2014 & $\begin{array}{l}\text { Nach neuesten Daten des Wirtschaftsministeriums wurden in Polen im ersten Halbjahr } 2014 \text { rund } 34 \text { Mio. Ton- } \\
\text { nen Steinkohle gefördert, dies sind 2,8 Mio. Tonnen weniger als im Vergleichszeitraum } 2013 .\end{array}$ \\
\hline 22.08 .2014 & $\begin{array}{l}\text { Das Wirtschaftsministerium teilt mit, dass die ressortübergreifende Arbeitsgruppe zum Betrieb der Steinkohle- } \\
\text { bergwerke zurzeit vor allem die Finanzierung der Branche, die Liquidität der Kohlekonzerne, Fragen des Ener- } \\
\text { gieimports und die Organisation des Kohleverkaufs behandelt. Vorläufige Empfehlungen gälten einer Steigerung } \\
\text { der Nachfrage nach polnischer Kohle sowie einer Umstrukturierung der Branche. Die Arbeitsgruppe wurde im } \\
\text { Mai von Ministerpräsident Donald Tusk berufen. }\end{array}$ \\
\hline 23.08 .2014 & $\begin{array}{l}\text { Das polnische Außenministerium verurteilt in einer Erklärung den Grenzübertritt russischer Hilfstransporte } \\
\text { auf ostukrainisches Gebiet ohne die Erlaubnis Kiews als eine weitere Verletzung des internationalen Rechts von } \\
\text { Seiten Russlands, was zu einer Eskalation des russisch-ukrainischen Konflikts führen und die Chancen auf Ver- } \\
\text { ständigung verringern werde. Polen unterstütze alle Bemühungen, den Konflikt in der Ukraine unter Wahrung } \\
\text { der Souveränität und territorialen Integrität der Ukraine beizulegen. }\end{array}$ \\
\hline
\end{tabular}




\begin{tabular}{|c|c|}
\hline 24.08 .2014 & $\begin{array}{l}\text { Aus Anlass des 23. Jahrestages der Erlangung der Unabhängigkeit der Ukraine unterstreicht Staatspräsident } \\
\text { Bronisław Komorowski in einem Brief an den Präsidenten der Ukraine, Petro Poroschenko, das Recht der Ukraine } \\
\text { auf Verteidigung und auf die unabhängige Wahl eines Entwicklungsmodells für den ukrainischen Staat. Polen sei } \\
\text { über die neuesten Fälle der Verletzung internationalen Rechtes im ukrainisch-russischen Konflikt zutiefst beun- } \\
\text { ruhigt und verurteile die Aggressionen Russlands. }\end{array}$ \\
\hline 25.08.2014 & $\begin{array}{l}\text { In Allenstein (Olsztyn) richtet Polen die zweitägige Parlamentarische Ostseekonferenz aus, an der ca. } 200 \text { Perso- } \\
\text { nen, darunter Vertreter von elf Staatsparlamenten, elf Regionalparlamenten und fünf parlamentarischen Orga- } \\
\text { nisationen, teilnehmen. Diskutiert werden u. a. die Zusammenarbeit im Ostseeraum, ökologische Aufgaben und } \\
\text { das kulturelle Erbe des Ostseeraums. Auch Vertreter Russlands sind anwesend. Die Parlamentarische Ostsee- } \\
\text { konferenz findet zum 23. Mal statt; } 1991 \text { wurde sie in Helsinki als Forum des politischen Dialogs zwischen den } \\
\text { Parlamentariern der Region ins Leben gerufen. }\end{array}$ \\
\hline 26.08 .2014 & $\begin{array}{l}\text { Nach neuesten Angaben des Statistischen Hauptamtes (Główny Urząd Statystyczny - GUS) betrug die Arbeits- } \\
\text { losenquote im Juli 11,9\% (Juni 2014: 12\%). }\end{array}$ \\
\hline 27.08.2014 & $\begin{array}{l}\text { Ministerpräsident Donald Tusk bestätigt im Sejm auf der Grundlage von Informationen der NATO und des pol- } \\
\text { nischen Geheimdienstes, dass in der Ostukraine russische operative Einheiten stationiert seien. Angesichts des } \\
\text { Konfliktes zwischen Russland und der Ukraine werde sich Polen schrittweise um eine stärkere Verankerung in } \\
\text { der NATO bemühen. Von den polnischen Parlamentariern erwarte er Unterstützung für die Erhöhung der Ver- } \\
\text { teidigungsausgaben auf } 2 \% \text { des Bruttoinlandsprodukts ab dem Jahr 2016, so Tusk. }\end{array}$ \\
\hline 28.08.2014 & $\begin{array}{l}\text { Die Tageszeitung "Rzeczpospolita« teilt die vom Außenministerium bestätigte Information mit, dass Außen- } \\
\text { minister Radosław Sikorski die Entscheidung unterzeichnet habe, das Generalkonsulat der Republik Polen in } \\
\text { Sewastopol auf der Halbinsel Krim aufzulösen. }\end{array}$ \\
\hline 29.08.2014 & $\begin{array}{l}\text { Nach vorläufigen Angaben des Statistischen Hauptamtes (Główny Urząd Statystyczny - GUS) betrug das Brut- } \\
\text { toinlandsprodukt im zweiten Quartal } 2014 \text { 3,3\%. Dabei belief sich der Anstieg der Inlandsnachfrage auf 5,1 \% } \\
\text { (erstes Quartal 2014: 3,0\%). }\end{array}$ \\
\hline 30.08 .2014 & $\begin{array}{l}\text { Auf dem EU-Gipfel in Brüssel einigen sich die Staats- und Regierungschefs der } 28 \text { Mitgliedsländer auf Minis- } \\
\text { terpräsident Donald Tusk als EU-Ratspräsidenten. Seine Amtszeit beginnt am 1. Dezember } 2014 .\end{array}$ \\
\hline 01.09.2014 & $\begin{array}{l}\text { Auf der Westerplatte in Danzig (Gdańsk) findet die zentrale Gedenkfeier aus Anlass des Beginns des Zweiten } \\
\text { Weltkrieges vor } 75 \text { Jahren statt. Ministerpräsident Donald Tusk unterstreicht, dass heute noch Zeit sei, diejeni- } \\
\text { gen in Europa und der Welt aufzuhalten, für die Gewalt wieder ein Mittel der politischen Auseinandersetzung } \\
\text { geworden sei. Auf dem kommenden NATO-Gipfel in Wales werde über eine neue Sicherheitspolitik entschieden } \\
\text { werden, um wirksam gegen Kriegsgefahren nicht nur in der Ostukraine vorzugehen zu können. Weitere Redner } \\
\text { sind Staatspräsident Bronisław Komorowski und Bundespräsident Joachim Gauck. }\end{array}$ \\
\hline
\end{tabular}

Sie können die gesamte Chronik seit 2007 auch auf <http://www.laender-analysen.de/polen/> unter dem Link »Chronik« lesen. 
Die Polen-Analysen erscheinen zweimal monatlich als E-Mail-Dienst. Sie werden gemeinsam vom Deutschen PolenInstitut Darmstadt, der Bremer Forschungsstelle Osteuropa und der Deutschen Gesellschaft für Osteuropakunde in Partnerschaft mit dem Willy Brandt Zentrum für Deutschland- und Europastudien an der Universität Wroclaw (Breslau) herausgegeben.

Ein Archiv der Polen-Analysen finden Sie im Internet unter <www.laender-analysen.de/polen>

Kostenloses Abonnement unter <http://www.deutsches-polen-institut.de/Newsletter/subscribe.php>

Diese Analysen finden Sie online als Lizenzausgabe auf $<$ bpb.de>

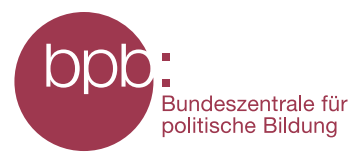

\section{Deutsches Polen-Institut Darmstadt}

Das Deutsche Polen-Institut Darmstadt (DPI) ist ein Forschungs-, Informations-, und Veranstaltungszentrum für polnische Kultur, Geschichte, Politik, Gesellschaft und die deutsch-polnischen Beziehungen, die sich im Kontext der europäischen Integration entwickeln. Das seit März 1980 aktive und bis 1997 von Gründungsdirektor Karl Dedecius geleitete Institut ist eine Gemeinschaftsgründung der Stadt Darmstadt, der Länder Hessen und Rheinland-Pfalz sowie des Bundes. 1987 wurden die Kultusminister der Länder und 2011 das Auswärtige Amt weitere institutionelle Träger. Einen wesentlichen Beitrag zur Verwirklichung der Institutsziele leisten private Stiftungen. Das DPI hat satzungsgemäß die Aufgabe, durch seine Arbeit zur Vertiefung der gegenseitigen Kenntnisse des kulturellen, geistigen und gesellschaftlichen Lebens von Polen und Deutschen beizutragen.

Ziel der Vermittlertätigkeit des DPI ist es, „die zu interessieren, auf die es politisch, wirtschaftlich, gesellschaftlich und kulturell im deutsch-polnischen Verhältnis ankommt« (Leitlinien 1997). Es geht um die Entscheider und Multiplikatoren in Politik, Kultur, Bildung, Verwaltung, Medien und Wirtschaft und, wesentlich stärker ausgeprägt als bisher, um das Hineinwirken in Wissenschaft, Forschung und Bildung.

Derzeit bemüht sich das DPI in Kooperation mit den verstreuten Orten wissenschaftlicher Polen-Kompetenz an deutschen Hochschulen und Forschungsinstituten verstärkt darum, ausgehend von einer Bestandsaufnahme deutscher Polen-Forschung Ort wissenschaftlicher Forschung und verbindendes, vernetzendes und kooperierendes Zentrum zu werden. Ausgangspunkt der Neuausrichtung ist die kaum mehr kontrollierbare Dynamik des Rückbaus der Ressourcen der wissenschaftlichen Polen-Kompetenz in den unterschiedlichen Disziplinen. Mit der über 60.000 Bände zählenden multidisziplinären Fachbibliothek für Polen, die eine einzigartige Sammlung polnischer Literatur in der Originalsprache und in deutscher Übersetzung umfasst, ist das DPI bereits ein geschätzter Ort der Recherche und des wissenschaftlichen Arbeitens. (www.deutsches-polen-institut.de)

Forschungsstelle Osteuropa an der Universität Bremen (www.forschungsstelle.uni-bremen.de)

1982 gegründet, widmet sich die Forschungsstelle Osteuropa an der Universität Bremen der interdisziplinären Analyse der Länder Ost- und Ostmitteleuropas in Zeitgeschichte und Gegenwart. Der Forschungsschwerpunkt liegt dabei auf der Rolle von »Dissens und Konsens«, von Opposition und Zivilgesellschaft in ihrem historischen, politischen, gesellschaftlichen und kulturellen Kontext. Die Forschungsstelle besitzt in ihrem Archiv eine einzigartige Sammlung alternativer Kulturgüter und unabhängiger Texte aus den ehemaligen sozialistischen Ländern. Darunter befindet sich auch eine umfangreiche Sammlung des "Zweiten Umlaufs«, die das Schrifttum und Dokumente unabhängiger Initiativen und gesellschaftlicher Gruppen in Polen aus der Zeit von 1976 bis zum Umbruch umfasst. Hinzu kommt eine umfangreiche Bibliothek mit wissenschaftlicher Literatur. Mit Archiv, Bibliothek und zwei wissenschaftlichen Abteilungen ist die Forschungsstelle auch eine Anlaufstelle sowohl für Gastwissenschaftler als auch für die interessierte Öffentlichkeit.

Eine der Hauptaufgaben der Forschungsstelle ist die Information der interessierten Öffentlichkeit. Dazu gehören unter anderem regelmäßige E-Mail-Informationsdienste für Politik, Wirtschaft, Zivilgesellschaft und Medien.

\section{Herausgegeben mit finanzieller Unterstützung der Stiftung für deutsch-polnische Zusammenarbeit}

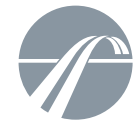

FUNDACJA WSPÓEPRACY

POLSKO-NIEME
STIFTUNG

STIFTUNG

FÜR DEUTSCH-POLNISC
ZUSAMMENARBEIT

Die Meinungen, die in den Polen-Analysen geäußert werden, geben ausschließlich die Auffassung der Autoren wieder.

Abdruck und sonstige publizistische Nutzung sind nach Rücksprache mit der Redaktion gestattet.

Redaktion: Prof. Dr. Dieter Bingen (verantwortlich) (Darmstadt), Silke Plate, M.A. (Bremen) Technische Gestaltung: Matthias Neumann

Polen-Analysen-Layout: Cengiz Kibaroglu, Matthias Neumann

Alle Ausgaben der Polen-Analysen sind mit Themen- und Autorenindex archiviert unter www.laender-analysen.de

Die Polen-Analysen werden im Rahmen der Datenbank World Affairs Online (WAO) ausgewertet und sind im Portal IREON www.ireon-portal.de recherchierbar.

ISSN 1863-9712 @ 2014 by Deutsches Polen-Institut Darmstadt und Forschungsstelle Osteuropa, Bremen

Kontakt: Dr. Andrzej Kaluza, Presse- und Öffentlichkeitsarbeit, Deutsches Polen-Institut, Mathildenhöhweg 2,

D-64287 Darmstadt, Tel.: 06151/4985-13, Fax: 06151/4985-10, E-Mail: polen-analysen@dpi-da.de, Internet: www.laender-analysen.de/polen 